\title{
Neurosteroids and $\mathrm{GABA}_{A}$ receptor interactions: a focus on stress
}

\section{Benjamin G. Gunn, Adam R. Brown, Jeremy J. Lambert and Delia Belelli*}

Division of Neuroscience, Medical Research Institute, Ninewells Hospital and Medical School, Ninewells Hospital, University of Dundee, Dundee, UK

Edited by:

Kazuyoshi Tsutsui, Waseda University, Japan

Reviewed by:

Michael Schumacher, INSERM,

France

Rainer Rupprecht, University

Regensburg, Germany

*Correspondence:

Delia Belelli, Division of

Neuroscience, Medical Research

Institute, Ninewells Hospital and

Medical School, Ninewells Hospital,

University of Dundee, Dundee DD1

9SY, UK.

e-mail:d.belelli@dundee.ac.uk
Since the pioneering discovery of the rapid CNS depressant actions of steroids by the "father of stress," Hans Seyle 70 years ago, brain-derived "neurosteroids" have emerged as powerful endogenous modulators of neuronal excitability. The majority of the intervening research has focused on a class of naturally occurring steroids that are metabolites of progesterone and deoxycorticosterone, which act in a non-genomic manner to selectively augment signals mediated by the main inhibitory receptor in the CNS, the GABA $A_{A}$ receptor. Abnormal levels of such neurosteroids associate with a variety of neurological and psychiatric disorders, suggesting that they serve important physiological and pathophysiological roles. A compelling case can be made to implicate neurosteroids in stress-related disturbances. Here we will critically appraise how brain-derived neurosteroids may impact on the stress response to acute and chronic challenges, both pre- and postnatally through to adulthood. The pathological implications of such actions in the development of psychiatric disturbances will be discussed, with an emphasis on the therapeutic potential of neurosteroids for the treatment of stress-associated disorders.

\section{INTRODUCTION}

In the 1940s, the Hungarian endocrinologist, Dr. Hans Selye demonstrated that certain pregnane steroids could induce sedation and anesthesia on a relatively rapid time scale, a property which precludes a genomic action (Selye, 1941). The molecular mechanism underlying the rapid depressant action of these pregnane steroids remained unknown until the early 1980s, when Harrison and Simmonds (1984) demonstrated that a structurally related synthetic steroidal anesthetic, alphaxalone ( $5 \alpha$-pregnane-3 $\alpha$-ol11,20 -dione), potently enhanced $\mathrm{GABA}_{\mathrm{A}}$ receptor $\left(\mathrm{GABA}_{\mathrm{A}} \mathrm{R}\right)$ function (a receptor for the main inhibitory neurotransmitter in the CNS) in a brain slice preparation. Subsequent studies revealed that certain endogenously synthesized steroids, such as the progesterone (PROG) metabolites $5 \alpha$-pregnan-3 $\alpha$-ol-20-one ( $5 \alpha 3 \alpha$ THPROG), $5 \beta$-pregnan- $3 \alpha$-ol-20-one (5 $53 \alpha-$ THPROG), and the deoxycorticosterone (DOC) metabolite $5 \alpha$-pregnan-3 $\alpha, 21$-diol20 -one ( $5 \alpha 3 \alpha$-THDOC), were similarly potent $(10-100 \mathrm{nM})$ positive allosteric modulators of $\mathrm{GABA}_{\mathrm{A}} \mathrm{R}$ function (Barker et al., 1987; Callachan et al., 1987; Gee et al., 1987, 1988; Harrison et al., 1987; Lambert et al., 1987, 2009; Peters et al., 1988). Indeed, the observed enhancement of $\mathrm{GABA}_{\mathrm{A}} \mathrm{R}$ function by such steroids was consistent with their behavioral actions (anxiolytic, anticonvulsant, sedative, analgesic, and anesthetic; Lambert et al., 1995; Gasior et al., 1999; Rupprecht, 2003). The subsequent demonstration that brain levels of neurosteroids occur within a range known to be active at the $\mathrm{GABA}_{\mathrm{A}} \mathrm{R}$ led to the proposal that they may act as endogenous regulators of $\mathrm{GABA}_{\mathrm{A}} \mathrm{R}$ function (reviewed in Lambert et al., 1995).

$\mathrm{GABA}_{\mathrm{A}}$ receptors are responsible for mediating the majority of fast inhibitory neurotransmission within the CNS and are the target of a number of clinically significant compounds, including benzodiazepines (BDZ) such as diazepam and a variety of structurally diverse general anesthetics and anticonvulsants, including propofol, etomidate, and members of the barbiturate class, e.g., thiopentone (Olsen and Sieghart, 2009). This receptor class possesses a pentameric structure, surrounding a central anion conducting pore. To date, 19 subunits have been identified $(\alpha 1-6, \beta 1-3, \gamma 1-3, \delta, \varepsilon, \theta, \pi, \rho 1-3)$, that are divided into subfamilies based upon their amino acid homology (Olsen and Sieghart, 2008, 2009). These subunits exhibit distinct expression profiles and allow for the expression of $\sim 20-30$ different $\mathrm{GABA}_{\mathrm{A}} \mathrm{R}$ isoforms within the mammalian CNS (Fritschy and Brunig, 2003; Olsen and Sieghart, 2008). The subunit composition regulates the pharmacological and biophysical properties of the $G_{A B A} R$ (Olsen and Sieghart, 2009), in addition to influencing the regional expression and cellular location (e.g., synaptic or extrasynaptic). $\mathrm{GABA}_{\mathrm{A}} \mathrm{R}$ isoforms incorporating the $\gamma 2$ subunit, in combination with $\alpha$ and $\beta$ subunits are ubiquitously expressed throughout the brain (Wisden et al., 1992; Fritschy and Brunig, 2003) and are predominantly, but not exclusively, located within the synapse, where they are responsible for mediating "phasic" GABAergic inhibition (Farrant and Nusser, 2005). In contrast, $\delta$-containing $\mathrm{GABA}_{\mathrm{A}} \mathrm{Rs}$ $\left(\delta-G_{A B A} R s\right)$ display a more discrete expression profile, being primarily prevalent in the cerebellum, dentate gyrus, thalamus, striatum, and cortex (Wisden et al., 1992; Fritschy and Mohler, 1995) where they are expressed only at peri- and extrasynaptic locations (Nusser et al., 1998; Wei et al., 2003) and mediate a "tonic" form of GABAergic inhibition (Farrant and Nusser, 2005).

The apparent sensitivity of native $\mathrm{GABA}_{\mathrm{A}} \mathrm{Rs}$ to neurosteroid modulation is influenced by a variety of factors including the subunit composition of the receptor, phosphorylation reactions, and local metabolism (Belelli and Lambert, 2005). As an example of the first, evidence from recombinant expression systems indicates 
that $\delta-G_{A B A}$ Rs are significantly more sensitive to modulation by endogenous neurosteroids, than their $\gamma 2$-containing counterparts (Belelli et al., 2002; Brown et al., 2002). However, the preferential interaction with $\delta-G_{A B A}$ Rs is secondary to GABA acting as a partial agonist at this receptor subtype, thus allowing for the magnitude of the steroid response to be significantly greater than for the homologous $\gamma 2$-containing receptors (Bianchi and Macdonald, 2003). Consequently, neurosteroid modulation of extrasynaptic $\delta-G_{A B A}$ Rs has received considerable attention and these receptors have been proposed to play an important role in mediating the physiological effects of these compounds (Maguire and Mody, 2009). However, it should be noted that endogenous neurosteroids display neuron-specific actions upon $\mathrm{GABA}_{\mathrm{A}} \mathrm{R}$ function and that certain synaptic ( $\gamma 2$-containing) $\mathrm{GABA}_{\mathrm{A}}$ Rs are similarly sensitive to physiological neurosteroid concentrations in specific brain regions (Cooper et al., 1999; Herd et al., 2007; Belelli et al., 2009).

Recent site-directed mutagenesis studies have revealed that the activation and potentiation of $\mathrm{GABA}_{\mathrm{A}} \mathrm{Rs}$ by endogenous neurosteroids are mediated by two discrete groups of amino acid residues, housed in the $\mathrm{GABA}_{\mathrm{A}} \mathrm{R}$ transmembrane domains (Hosie et al., 2006). Thus, $\alpha \mathrm{T} 236$ and $\beta Y 284$ regulate neurosteroid (i.e., $5 \alpha 3 \alpha$-THPROG and $5 \alpha 3 \alpha$-THDOC)-induced $\mathrm{GABA}_{\mathrm{A}} \mathrm{R}$ activation, whilst $\alpha \mathrm{Q} 241$ and $\alpha \mathrm{N} 407$ are implicated in the GABAmodulatory effects of these steroids (Hosie et al., 2006). However, subsequent studies have suggested the neurosteroid binding pocket to have a more complex structure with additional residues, e.g., $\alpha 1 S 240$ contributing to the modulatory actions of steroid molecules of different structure (Akk et al., 2008). Of relevance to the interaction of neurosteroids with $\delta-G_{A B A} R s$, GABA-evoked currents mediated by recombinant $\alpha 4 \beta 3 \delta$ receptors in which the critical glutamine residue of the $\alpha 4$ subunit was mutated ( $\alpha 4 \mathrm{Q} 246 \mathrm{~L}$ ) are insensitive to $5 \alpha 3 \alpha$-THDOC. This observation suggests that the $\delta$ subunit does not contribute directly to the GABA-modulatory neurosteroid binding site (Hosie et al., 2009).

It has been postulated that the differential accumulation of neurosteroids within the lipid membrane (due to their lipophilicity) serves to increase their local concentration, and as such, these steroids may diffuse laterally, through the membrane, to access low affinity binding site(s) on $\mathrm{GABA}_{\mathrm{A}} \mathrm{Rs}$, a proposal consistent with a putative transmembrane docking site (Akk et al., 2005; Chisari et al., 2010).

Within the brain, the levels of endogenous steroids derived from either central, or peripheral sources, are sufficient to mod-

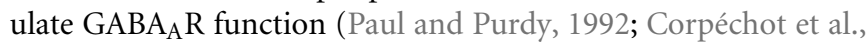
1993; Mellon and Vaudry, 2001; Mellon and Griffin, 2002). Initial studies suggested that steroid synthesizing enzymes were primarily expressed in glia (Melcangi et al., 1993). However, it is now apparent that the enzymes necessary for steroidogenesis are also expressed in certain neurons (Tsutsui, 2008; Do Rego et al., 2009) Therefore, as originally postulated, neurosteroids may function as endocrine messengers, but could additionally act in a paracrine, or indeed autocrine manner as local neuromodulators to "fine tune" inhibitory transmission (Agis-Balboa et al., 2006). Interestingly, the endogenous levels of neurosteroids within the CNS are not static, but are dynamically regulated in response to a number of physiological states, including development, stress, puberty, pregnancy, and during the ovarian cycle (Purdy et al., 1991; Paul and Purdy, 1992; Maguire and Mody, 2009; Shen et al., 2010). A number of psychological conditions, including panic attacks, major depression, postpartum depression, premenstrual tension, and schizophrenia, have been associated with perturbations in the levels of neurosteroids within the CNS (Purdy et al., 1991; Eser et al., 2006; Smith et al., 2006; Uzunova et al., 2006; Longone et al., 2008), while treatment with certain psychoactive drugs (e.g., ethanol, fluoxetine) can perturb the levels of these neurosteroids (Uzunova et al., 1998; Sundstrom-Poromaa, 2004; Biggio et al., 2007).

This review will focus on the impact of endogenous neurosteroids upon inhibitory transmission within the CNS in both physiological and pathophysiological scenarios, with an emphasis on their documented and potential role within the stress neurocircuitry.

\section{THE INFLUENCE OF "LOCAL" NEUROSTEROIDS ON NEURONAL INHIBITION: PHYSIOLOGICAL RELEVANCE}

As noted above and discussed further below, several lines of evidence are consistent with the proposal that $\mathrm{GABA}_{\mathrm{A}} \mathrm{R}$-mediated inhibition may be subject to fine tuning by locally produced steroids. Although a significant proportion of these neurosteroids are derived from peripheral sources including the adrenal cortex and the ovaries (Paul and Purdy, 1992), the brain is a steroidogenic organ, capable of de novo synthesis of these neuromodulators (Purdy et al., 1991; Mellon, 2004; Agis-Balboa et al., 2006; Do Rego et al., 2009). Thus, the enzymes and mitochondrial transporters necessary for the synthesis of $\mathrm{GABA}_{\mathrm{A}} \mathrm{R}$-active pregnane steroids are expressed in the CNS. The synthesis of $5 \alpha 3 \alpha$-THPROG and $5 \alpha 3 \alpha$-THDOC from PROG and DOC respectively, requires two sequential reactions catalyzed by $5 \alpha$-reductase and $3 \alpha$-hydroxysteroid dehydrogenase $(3 \alpha-\mathrm{HSD}$; Karavolas and Hodges, 1990; Figure 1). These key enzymes are expressed within the CNS in a region-specific manner and often, are co-localized (Agis-Balboa et al., 2006). Furthermore, the expression of these enzymes is not limited to GABAergic neurons. Thus, for example both enzymes are selectively expressed in glutamatergic principal neurons in the cortex and hippocampus, whilst in the cerebellum and thalamus their co-expression is restricted to Purkinje and nucleus reticularis thalami (nRT) neurons, which are GABAergic (Agis-Balboa et al., 2006; Tsutsui, 2008). These observations raise the prospect that the excitability of neurons, which coexpress $\mathrm{GABA}_{\mathrm{A}}$ Rs and the steroid synthesizing enzymes may be self-regulated by the neurosteroid acting in an autocrine manner (Agis-Balboa et al., 2006; Herd et al., 2007; Figure 2).

Recent experimental evidence lends considerable support to the notion that locally produced neurosteroids can modulate neuronal excitability. At synaptic and extrasynaptic $\mathrm{GABA}_{\mathrm{A}} \mathrm{Rs}$ the effect of these neuromodulators is typically manifest as a prolongation of the decay time of inhibitory postsynaptic currents (IPSCs) and an increase in the tonic conductance respectively. The treatment ( 5 h previously) of mice with the $5 \alpha$-reductase inhibitor SKF 105111 (17 $\beta$-17-[bis (1methylethyl) amino carbonyl]; Figure 1) resulted in a reduction in the decay time of spontaneous IPSCs (sIPSCs) recorded from cortical neurons, suggesting the presence 


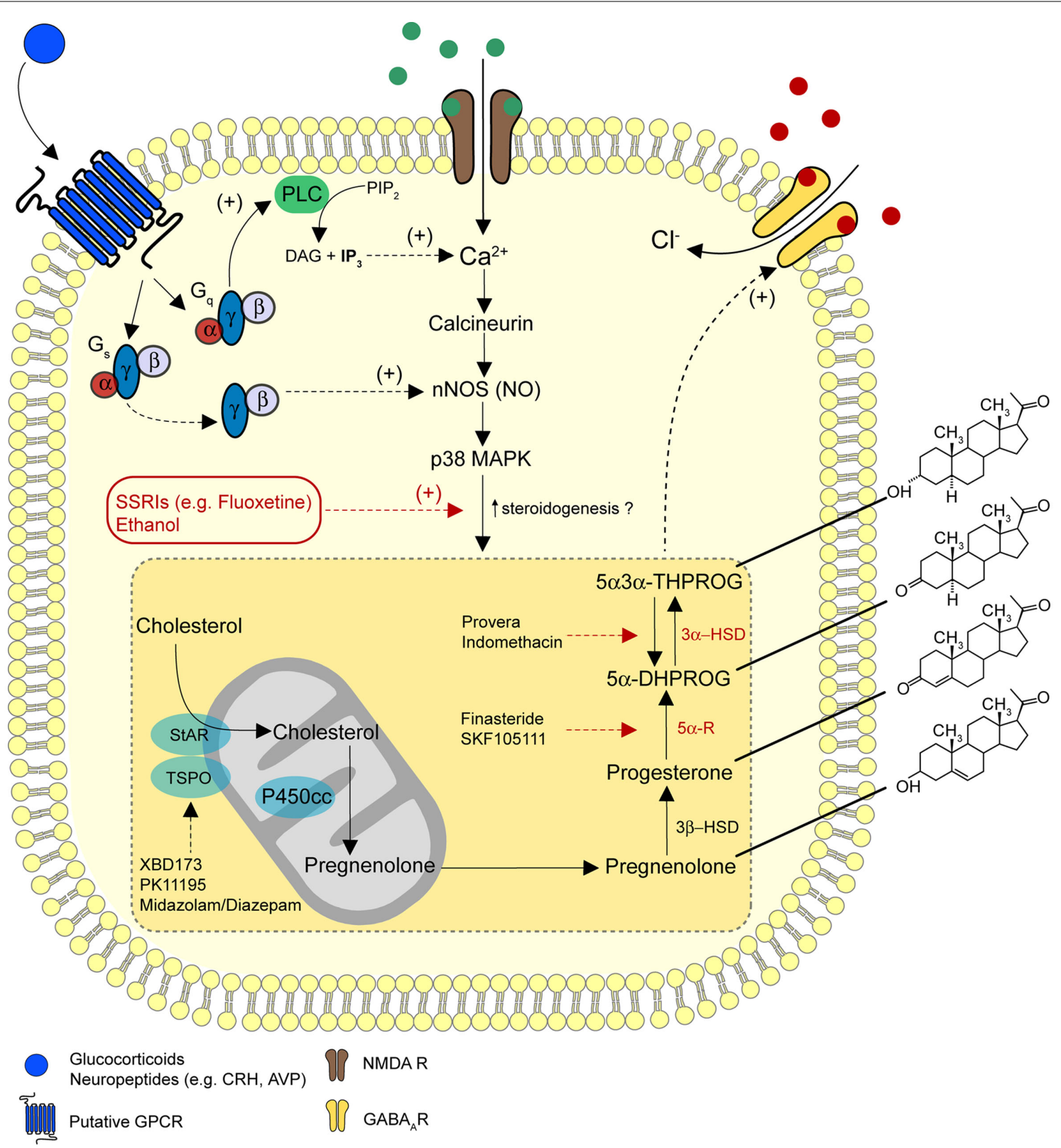

FIGURE 1 | A model for the regulation of neurosteroidogenesis. A diagrammatic representation of the pathways for the biosynthesis of $5 \alpha 3 \alpha$-THPROG from cholesterol. Receptors and signaling mechanisms potentially regulating steroidogenesis and sites of action of ligands used to target selective enzymatic pathways are additionally illustrated. In the proposed model, NMDA receptor activation may stimulate neurosteroidogenesis on a rapid time scale (Tokuda et al., 2011), possibly via the $\mathrm{Ca}^{2+}$ induced activation of nNOS and p38 MAPK (Izumi et al., 2008). In addition, glucocorticoids may regulate neurosteroidogenesis via rapid non-genomic effects through the activation of $\mathrm{G}_{\mathrm{s}}-\gamma \beta$, an effect that stimulates nNOS (Di et al., 2009). Furthermore, a number of stress-related neuropeptides (e.g., $\mathrm{CRH}, \mathrm{AVP}$ ), which are known to signal through $\mathrm{G}_{\mathrm{s}}$-coupled receptor complexes may modulate nNOS activity and thus influence neurosteroid synthesis. Receptors for these neuropeptides can additionally couple to $\mathrm{G}_{\mathrm{q}}$-proteins to raise intracellular $\mathrm{Ca}^{2+}$ levels and thus, couple to signaling cascades similar to those associated with NMDA receptor activation. These GPCR-dependent signaling pathways may provide a functional regulatory link between the stress axis and the de novo synthesis of $5 \alpha 3 \alpha-$ THPROG. of an endogenous neurosteroid tone in these cells (Puia et al., 2003). In the hippocampus, CA1 pyramidal neurons are sensitive to physiologically significant concentrations of $5 \alpha 3 \alpha$-THPROG $(100 \mathrm{nM})$, while the same concentration of the neurosteroid has no effect upon inhibitory transmission in dentate gyrus granule cells (DGGCs). However, the metabolically stable synthetic analog, ganaxolone, enhances inhibitory transmission at low concentrations in CA1 neurons and DGGCs (Belelli and Herd, 2003). Interestingly, $3 \alpha-\mathrm{HSD}$, unlike $5 \alpha$-reductase, is involved in both the synthesis and degradation of $5 \alpha 3 \alpha$-THPROG (and $5 \alpha 3 \alpha$ THDOC) as the cytosolic isoform catalyzes the reductive formation of $5 \alpha 3 \alpha$-THPROG from $5 \alpha$-dihydroprogesterone ( $5 \alpha$-DHP), 
A

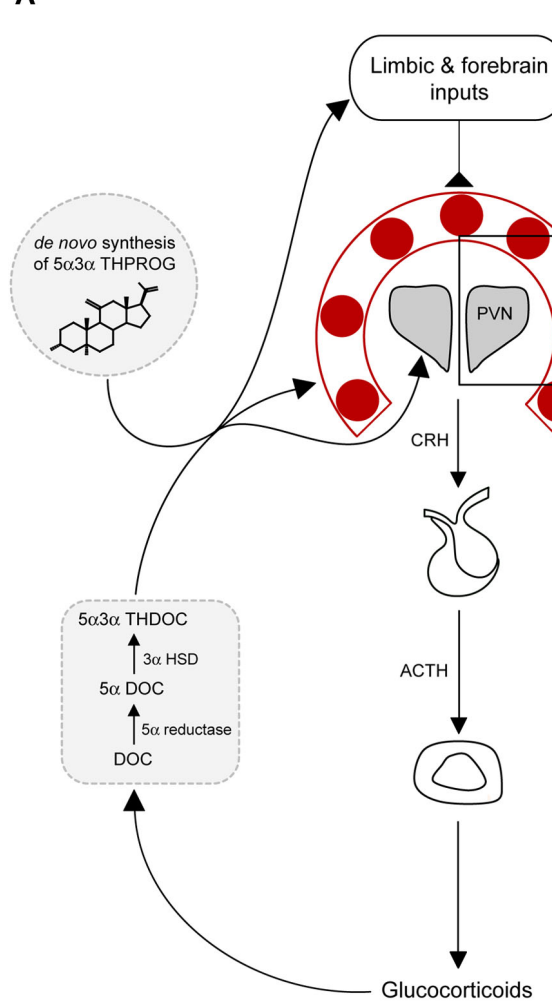

FIGURE 2 | A model for neurosteroid actions at the $\mathrm{GABA}_{A}$ receptor within the stress neurocircuitry. (A) A diagrammatic representation of the HPA axis. The release of $\mathrm{CRH}$ from the dorsal-medial parvocellular neurons (mpd) of the PVN is regulated by humoral negative feedback pathways and neuronal inputs from higher brain structures (e.g., the limbic system and the forebrain regions). Inputs from the forebrain and the limbic structures do not directly innervate the PVN, but form polysynaptic connections via a number of predominantly GABAergic "relay nuclei" (red) surrounding the PVN, such as the BST mPOA, DH, and peri-PVN (Cullinan et al., 2008). In the proposed model stress-induced endogenous neurosteroids derived from peripheral sources (e.g., $5 \alpha 3 \alpha-$ THDOC) and or synthesized de novo within the CNS (e.g., $5 \alpha 3 \alpha$-THPROG) may act to enhance the GABAergic inhibition in the PVN and surrounding neurons. Additionally, neurosteroids may modulate inhibitory transmission within limbic and forebrain regions to influence their neuronal output and hence HPA activity. (B) Physiological concentrations of $5 \alpha 3 \alpha-$ THPROG $(100 \mathrm{nM})$ dramatically reduce the frequency of action
B

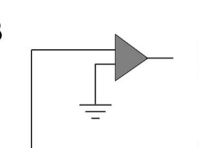

Control

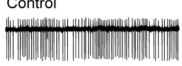

100 nM 5 $\alpha 3 \alpha-$ THPROG

T|| ||

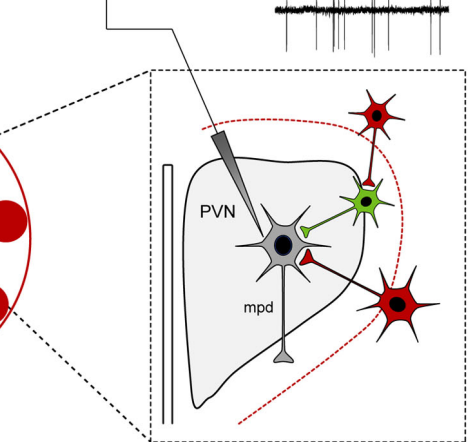

C

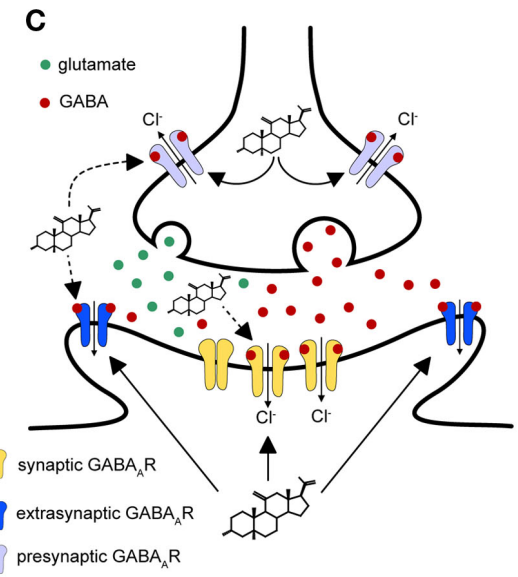

currents recorded from WT mpd neurons in a hypothalamic slice preparation containing the PVN and surrounding structures, thus inhibiting their output (i.e., CRH release). Local excitatory inputs (e.g., glutamatergic, green), which are themselves constrained by inhibitory GABAegic neuron (red) originating in the BST and local hypothalamic nuclei (Herman et al., 2002) drive the release of neuropeptides from mpd neuron (gray) of the PVN. (C) A diagrammatic representation of a representative PVN synapse (either GABAergic or glutamatergic). Neurosteroids (e.g., $5 \alpha 3 \alpha-$ THPROG) synthesized following a stressful challenge, may act both at presynaptic or postsynaptic locations in an autocrine or paracrine fashion respectively to enhance $G A B A_{A} R$ inhibition. Note that at presynaptic terminals due to the intraneuronal $\mathrm{Cl}^{-}$gradient, GABA may be depolarizing (Trigo et al., 2008) and thus neurosteroids may act to increase neurotransmitter release. Note that although extrasynaptic $\delta$-GABA $A_{A}$ receptors are absent in the PVN, other $\gamma 2-G_{B B A}$ Rs may be expressed extrasynaptically at GABAergic or glutamatergic synapses. whilst the membrane-bound isoform promotes the reverse, oxidative reaction (Li et al., 1997). In DGGCs the membrane-bound $3 \alpha$-HSD isoform is predominant, and the inhibition of this enzyme with indometacin, or the contraceptive agent Provera (Figure 1), results in a modest prolongation of miniature IPSCs (mIPSCs) and an enhancement of the endogenous tonic conductance of DGGCs (Belelli and Herd, 2003). Collectively, these observations are consistent with the proposal that local metabolism may play a crucial role in shaping $\mathrm{GABA}_{\mathrm{A}} \mathrm{R}$-mediated inhibition in a neuron-specific fashion.
The translocator protein $18 \mathrm{kDa}$ [TSPO; formerly the mitochondrial benzodiazepine receptor (MBR) or peripheral benzodiazepine receptor (PBR); Figure 1; Papadopoulos et al., 2006; Batarseh and Papadopoulos, 2010], is located on the outer mitochondrial membrane where it functions together with the steroidogenic acute regulator protein (StAR; Sierra, 2004; Figure 1) to transport cholesterol into mitochondria, a prerequisite and the rate-limiting step for steroid and neurosteroid synthesis (Rupprecht et al., 2010). The anxiolytic drug etifoxine, in addition to allosterically enhancing $\mathrm{GABA}_{\mathrm{A}} \mathrm{R}$ function, 
activates TSPO to increase the cerebral production of $5 \alpha 3 \alpha$ THPROG, an effect that contributes to the behavioral actions of the drug (Verleye et al., 2005). Moreover, the selective TSPO activator, XBD173 ( $N$-benzyl- $N$-ethyl-2-[7,8-dihydro-7-methyl8-oxo-2-phenyl-9H-purin-9-yl] acetamide; Figure 1) enhances the amplitude and duration of evoked IPSCs (eIPSCs) and mIPSCs recorded from neurons of the mouse medial prefrontal cortex (mPFC), an effect blocked by the $5 \alpha$-reductase inhibitor, finasteride (Rupprecht et al., 2009). Crucially, XBD173 is effective in tests predictive of an anxiolytic action [i.e., social isolation and elevated plus-maze (EPM) tests], with both actions being blocked by the TSPO antagonist PK11195 [1-(2-chlorophenylmethylpropyl)3-isoquinoline-carboxamide; Figure 1; Rupprecht et al., 2009]. Importantly, in humans XBD173 acts as an effective anxiolytic agent, without the sedative, or the withdrawal symptoms typically associated with current therapeutic treatments for anxiety (Rupprecht et al., 2009).

Certain benzodiazepines (BDZs), such as diazepam and midazolam not only act to enhance $\mathrm{GABA}_{\mathrm{A}} \mathrm{R}$ function, but also to promote the synthesis of neurosteroids through the activation of TSPO (Rupprecht et al., 2010; Tokuda et al., 2010; Figure 1). For example, in a brain slice preparation, midazolam, a BDZ used clinically to facilitate the induction of anesthesia, increased neurosteroid levels in CA1 pyramidal neurons and inhibited LTP (Tokuda et al., 2010). Consistent with a neurosteroid involvement, inhibiting neurosteroid synthesis with finasteride treatment, or inhibiting the GABA-modulatory actions of neurosteroids with the selective antagonist 17PA [17-phenyl- $(3 \alpha 5 \alpha)$-androst16-en-3-ol; Mennerick et al., 2004] significantly attenuated the actions of midazolam (Tokuda et al., 2010). Furthermore, in vivo finasteride pre-treatment blocked the inhibitory effects of midazolam upon contextual fear learning (Tokuda et al., 2010). In contrast, clonazepam, an anxiolytic, and anticonvulsant BDZ, does not induce changes to neurosteroid synthesis and has no effect upon LTP induction. However, when administered with the TSPO agonist FGIN (2-[2-(4-fluorophenyl)-1 $H$-indol-3-yl), or together with exogenous allopregnanolone, clonazepam produced similar effects to midazolam, thus inhibiting LTP induction (Tokuda et al., 2010). These observations suggest that the unique effects of certain clinically important BDZs may be mediated by the dual activation of TSPO and potentiation of $\mathrm{GABA}_{\mathrm{A}} \mathrm{R}$ function.

\section{PHYSIOLOGICAL AND PATHOPHYSIOLOGICAL ROLE OF NEUROSTEROIDS: A FOCUS ON STRESS INHIBITORY REGULATION OF THE STRESS CIRCUITRY}

The ability of an organism to adapt to conditions of stress is essential for survival and involves a number of finely regulated and highly conserved interconnected systems that maintain physiological homeostasis. The hypothalamic paraventricular nucleus (PVN) is a key brain region involved in initiating the neuroendocrine and autonomic response to stressor exposure (Herman and Cullinan, 1997). Within the PVN, spinally projecting parvocellular neurons (located in dorsal and ventromedial parvocellular regions), rapidly modulate autonomic output in response to stress exposure, while neuroendocrine parvocellular neurons (located in the dorsomedial parvocellular region), project to the median eminence and initiate activation of the hypothalamopituitary-adrenocortical (HPA) axis (Ulrich-Lai and Herman, 2009). Regulation of the HPA axis is mediated through the integration of hormonal feedback pathways, e.g., glucocorticoids, corticotrophin-releasing hormone (CRH), and a complex neurocircuitry involving a number of mono- and polysynaptic pathways (Herman et al., 2003; de Kloet et al., 2005; Ulrich-Lai and Herman, 2009; Figure 2A). The PVN receives considerable GABAergic innervation from local hypothalamic regions (e.g., dorsal hypothalamus, peri-PVN, preoptic area) and areas of the extended amygdala (e.g., bed nucleus of the stria terminalis, BST), that exert a substantial inhibitory tone upon the HPA axis (Cullinan et al., 2008). Forebrain and limbic regions (e.g., hippocampus, amygdala, and prefrontal cortex) do not directly innervate the PVN, but instead modulate HPA activity via projections to a number of these GABAergic nuclei surrounding the PVN (Ulrich-Lai and Herman, 2009; Figure 2A). As such, these "relay nuclei" are important sites of stress integration, located "upstream" of the PVN and it is conceivable that the modulation of inhibitory transmission at this level by neurosteroids, may play a role in this synaptic integration (Figure 2A).

Quantitative ultrastructural analysis has revealed that CRHreleasing parvocellular neurons are the main target for GABAergic inputs to the medial parvocellular region of the PVN (Miklos and Kovacs, 2002). Furthermore, dual in situ hybridization studies have demonstrated the mRNA expression of multiple $\mathrm{GABA}_{\mathrm{A}} \mathrm{R}$ subunits $(\alpha 1, \alpha 2, \beta 1-3$, and $\gamma 1, \gamma 2)$ in the majority of CRHreleasing neurons (Cullinan, 2000), providing molecular evidence for a role of $\mathrm{GABA}_{\mathrm{A}} \mathrm{R}$-mediated inhibition at the level of the HPA axis. In agreement with this anatomical data, electrophysiological recordings from acute hypothalamic slice preparations revealed that glutamate microinjection into regions surrounding the PVN elicited postsynaptic potentials sensitive to the $G_{A B A} R$ antagonist bicuculline in a significant proportion of parvocellular neurons (Boudaba et al., 1996), while bicuculline also increased the frequency of action currents in these neurons (Hewitt et al., 2009). Furthermore, the microinjection of bicuculline into the PVN in vivo resulted in increased plasma corticosterone levels (Cullinan et al., 2008; Hewitt et al., 2009), whilst in contrast, microinjection of the $\mathrm{GABA}_{\mathrm{A}} \mathrm{R}$ agonist muscimol reduced the circulating levels of this steroid (Cullinan et al., 2008). Collectively, these observations suggest that $\mathrm{GABA}_{\mathrm{A}} \mathrm{R}$-mediated inhibition is important for the regulation of HPA axis activity. Given this prominent role for GABA within the local stress neurocircuitry, it is conceivable that the rapid elevation of neurosteroid levels that occurs during stress (Purdy et al., 1991), may act as a brake upon HPA axis activity by enhancing the GABAergic inhibition exerted upon the PVN (Figure 2A). Indeed, the steroid synthesizing enzymes $5 \alpha$-reductase and $3 \alpha-\mathrm{HSD}$ are expressed and $5 \alpha 3 \alpha$-THPROG immunoreactivity can be detected within the hypothalamus and extended amygdala respectively (Li et al., 1997; Eechaute et al., 1999; Gao et al., 2002; Saalmann et al., 2007). Therefore, locally produced neurosteroids could potentially contribute to the control of HPA activity.

The following section will discuss the physiological and pathophysiological roles of endogenous neurosteroids in acute and chronic stress. 


\section{ACUTE STRESS}

Early behavioral studies demonstrated the anxiolytic properties of pregnane steroids in a variety of animal models of anxiety (Crawley et al., 1986; Bitran et al., 1995; Carboni et al., 1996). In addition, the levels of $5 \alpha 3 \alpha$-THPROG and $5 \alpha 3 \alpha$-THDOC were rapidly elevated in the rodent hypothalamus and cortex following exposure to an acute swim stress (Purdy et al., 1991). Interestingly, adrenalectomy prevented the stress-induced increase in brain levels of $5 \alpha 3 \alpha$-THDOC, but not $5 \alpha 3 \alpha$-THPROG demonstrating the de novo synthesis of the latter neurosteroid in response to stress (Purdy et al., 1991). Similarly, elevated levels of $5 \alpha 3 \alpha$-THDOC, following exposure to an acute swim stress, raised the threshold of pentylenetetrazol (PTZ)-induced seizures in a finasterideand indometacin-sensitive manner (Reddy and Rogawski, 2002). Collectively, these observations suggest that neurosteroids synthesized de novo within the CNS together with those derived from peripheral sources (i.e., $5 \alpha 3 \alpha$-THDOC from the adrenal cortex; Eser et al., 2005) may play a physiological role in modulating the stress response.

In electrophysiological recordings made from neonatal mouse [postnatal (PN) days 18-24] hypothalamus, we find low concentrations $(10-100 \mathrm{nM})$ of $5 \alpha 3 \alpha$-THPROG to enhance the synaptic inhibition of neuroendocrine parvocellular neurons of the PVN and to inhibit their output (Belelli et al., 2009; Figure 2B). In common, the output of spinally projecting parvocellular neurons is similarly reduced by low concentrations of $5 \alpha 3 \alpha$-THDOC (Womack et al., 2006). Neuroendocrine parvocellular neurons are known to activate the HPA axis through the release of CRH (Vale et al., 1981) and i.c.v. injection of this neuropeptide induces behaviors closely resembling those associated with stress and anxiety (Owens and Nemeroff, 1991). Interestingly, the anxiogenic effects of CRH in rats exposed to the EPM were inhibited in a dose-dependent manner by pre-treatment with $5 \alpha 3 \alpha$-THPROG (Patchev et al., 1994). Additionally, although having no effect upon basal $\mathrm{CRH}$ release in vitro, $5 \alpha 3 \alpha$-THPROG did suppress the methoxamine [an $\alpha 1$-adrenoreceptor ( $\alpha 1$-AR) agonist]-induced release of this neuropeptide (Patchev et al., 1994). This in vitro observation is intriguing given that the parvocellular region of the PVN receives considerable noradrenergic inputs from the nucleus of the solitary tract and the locus coeruleus (Cunningham and Sawchenko, 1988). Both of these structures are believed to trigger responses to "physical" stressors, an effect that is possibly mediated via a contribution by $\alpha 1$-ARs (Daftary et al., 2000; Han et al., 2002).

The magnitude and polarity of $\mathrm{GABA}_{\mathrm{A}} \mathrm{R}$-mediated neurotransmission is critically dependent upon the transmembrane $\mathrm{Cl}^{-}$ gradient. Thus, generally, an increase in the intracellular $\mathrm{Cl}^{-}$concentration can shift the GABA-mediated response from neuronal hyperpolarization (inhibitory) to depolarization (excitatory). The transmembrane $\mathrm{Cl}^{-}$gradient is maintained by cation-chloride co-transporters (CCC), with $\mathrm{Na}^{+}-\mathrm{K}^{+}-2 \mathrm{Cl}^{-}$co-transporter 1 (NKCC1) and $\mathrm{K}^{+}-\mathrm{Cl}^{-}$transporter 2 (KCC2) being responsible for the majority of neuronal $\mathrm{Cl}^{-}$uptake and extrusion respectively within the CNS. Crucially the relative functional expression of these transporters appears not to be static, but dynamically regulated during certain physiological (e.g., development) and pathophysiological states (reviewed in Blaesse et al., 2009). Interestingly, a recent study has suggested that exposure to acute restraint stress functionally down-regulates KCC2 such that the action of GABA in neuroendocrine parvocellular neurons shifts from being hyperpolarizing to depolarizing, thus profoundly weakening synaptic inhibitory transmission (Hewitt et al., 2009). The authors postulate that activation of $\alpha 1$-ARs underlies the depolarizing shift in the reversal potential for GABA ( $\left.\mathrm{E}_{\mathrm{GABA}}\right)$, most likely via the activation of protein kinase $\mathrm{C}$ (PKC). The ability of secondary messenger systems to indirectly and dynamically modulate the inhibitory tone exerted upon the HPA axis through changes in KCC2 function may be an important mechanism in the initiation and termination of the physiological response triggered by stress. Intriguingly, GABAergic transmission (measured by $\left[{ }^{35} \mathrm{~S}\right] t$-butylbicyclophosphorothionate (TBPS) binding and ${ }^{36} \mathrm{Cl}^{-}$uptake), has long been known to be rapidly (within $5 \mathrm{~min}$ ) decreased following various forms of acute stress (Sanna et al., 1992; Barbaccia et al., 1996; reviewed in Biggio et al., 2007), whereas the subsequent increases in brain and plasma neurosteroid levels peaked $30 \mathrm{~min}$ after the onset of stress and was correlated with the restoration of GABAergic transmission and reduced anxiety-like behavior (Barbaccia et al., 2001). These findings support the proposal that the neuroendocrine and autonomic responses to a stressor may be modulated by these endogenous neurosteroids, which in this scenario would act to terminate the stress response. Nevertheless, although as noted above the enzymes are expressed within this region (Eechaute et al., 1999), it remains to be determined whether these neurosteroids are actually produced de novo, specifically in the PVN and nearby surrounding regions in response to a stressful challenge.

DOC mediates many of the physiological responses to acute stress (Reddy, 2006). Thus, it is conceivable that metabolites of this steroid, e.g., $5 \alpha 3 \alpha$-THDOC may contribute to other stressinduced alterations in inhibitory transmission via their actions on the $\mathrm{GABA}_{\mathrm{A}} \mathrm{R}$ (Reddy, 2006). Indeed, the exposure of mice to a single acute hypoxic challenge increases expression of the $\mathrm{GABA}_{\mathrm{A}} \mathrm{R} \delta$ subunit in the hippocampus and enhances the $\mathrm{GABA}_{\mathrm{A}} \mathrm{R}$-mediated tonic conductance of DGGCs (Maguire and Mody, 2007). The incubation of brain slices for $30 \mathrm{~min}$ with $5 \alpha 3 \alpha$-THDOC followed by a 30 - to 120 -min washout period of the steroid, induced a similar increase in the tonic conductance of DGGCs (Maguire and Mody, 2007). The mechanism(s) responsible for this $5 \alpha 3 \alpha-$ THDOC-induced up-regulation of $\delta-G_{A B A} R s$ remain to be determined. However, the previously reported "glucocorticoidlike" effects of endogenous neurosteroids (Patchev et al., 1994, 1996) and the $\mathrm{GABA}_{\mathrm{A}} \mathrm{R}$-dependent modulation of neuropeptide expression (Cole and Sawchenko, 2002; Bali and Kovacs, 2003; Brunton et al., 2009) within the PVN may be relevant in this respect.

\section{CHRONIC STRESS}

Exposure to chronic or repeated stress induces significant structural and functional alterations within the stress neurocircuitry, which are primarily and initially involved in promoting adaptation by allostasis, but in the long term can have deleterious effects upon brain function (Joels et al., 2007; McEwen, 2010). Indeed, dysregulation of the HPA axis has been implicated in the pathogenesis of a number of psychiatric and neurological conditions including depression, post-traumatic stress disorder 
(PTSD), and Alzheimer's (Holsboer, 2000; Schule et al., 2009). Furthermore, the levels of endogenous neurosteroids in plasma and cerebrospinal fluid (CSF) are altered in patients suffering from various stress-related affective disorders (Uzunova et al., 2006).

\section{Neurosteroids, chronic stress, and brain plasticity}

Chronic stress exposure results in a number of functional and molecular adaptations including altered dendritic morphology in stress-related brain regions such as the mPFC (Radley et al., 2005, 2008; Liston et al., 2006; Goldwater et al., 2009), hippocampus (Woolley et al., 1990; Magarinos and McEwen, 1995), and amygdala (Mitra and Sapolsky, 2008). These alterations in dendritic morphology are accompanied by behavioral changes, including impaired cognitive function (Bodnoff et al., 1995), increased anxiety (Mitra and Sapolsky, 2008), and abnormal attentional set-shifting (Liston et al., 2006). Interestingly, the observed stress-induced dendritic remodeling appears to be reversible, provided animals receive appropriate recovery time following stress exposure (Radley et al., 2005; Goldwater et al., 2009). Chronic stress-induced morphological alterations appear to be mediated by both sex and stress hormones (e.g., estrogen, glucocorticoids) and are accompanied by changes in synapse formation and receptor expression (Joels et al., 2007; McEwen, 2010). Thus, the behavioral deficits associated with chronic stress may be a consequence of network disruption in corticolimbic areas, an effect that may be contributed by, and secondary to, the remodeling of dendritic architecture within these brain structures (Goldwater et al., 2009).

Relatively little is known regarding the influence that endogenous neurosteroids have upon the morphological alterations associated with chronic stress and major depression. However, the regenerative potential of $5 \alpha 3 \alpha$-THPROG has been explored in animal models of Alzheimer's disease, the pathogenesis of which has recently implicated chronic stress as a significant contributing factor (Sotiropoulos et al., 2011). The proliferative effects of neurosteroids have been demonstrated in vitro using cerebellar granule cells (Keller et al., 2004), rat hippocampal, and human cortical neural progenitor cells (Wang et al., 2005), raising the possibility that the regenerative potential of neurosteroids may be therapeutically beneficial (Wang et al., 2008). In a mouse model of Alzheimer's disease (3xTgAD), male adult (3 months old) 3xTgAD mice displayed significant reductions in cell proliferation in the hippocampal subgranular zone (SGZ) and behaviorally exhibited deficits in a hippocampal associative learning and memory task, i.e., trace eye blinking conditioning (Wang et al., 2010). Intriguingly, in the $3 x \operatorname{TgAD}$ mouse, $5 \alpha 3 \alpha$-THPROG, in a dose-dependent manner, significantly increased cell proliferation in the SGZ to levels found in corresponding wild type mice, whilst also reversing the cognitive deficits (Wang et al., 2010). Indeed, the survival of early progenitor cells in the $3 \times \operatorname{TgAD}$ mouse correlated with the enhanced memory performance produced by $5 \alpha 3 \alpha$-THPROG treatment, suggesting that early neurogenic deficits may contribute to the cognitive phenotype associated with Alzheimer's disease. Therefore, such neurosteroids may potentially serve as a regenerative therapeutic, to alter the development and progression of such neurodegenerative diseases (Wang et al., 2010). Indeed, a recent study has revealed that $5 \alpha 3 \alpha$-THPROG restored neural progenitor cell survival and associative learning and memory in adult male 3xTgAD mice that only exhibit intraneuronal amyloid $\beta(\mathrm{A} \beta$; i.e., $\leq 9$ months old). By contrast, the neurosteroid was ineffective in later stages of the disease (at the age of 12 months) when extraneuronal A $\beta$ plaques become apparent (Singh et al., 2011). Collectively, these findings indicate that the therapeutic efficacy of this neurosteroid is dependent upon the stage of AD pathology.

Intriguingly, there appears to be many similarities between the endocrine (e.g., hypersecretion of glucocorticoids) and neuronal (e.g., dendritic remodeling) modifications reported in the pathogenesis of both Alzheimer's and depression (Lupien et al., 2009). Thus, it is tempting to speculate that the regenerative potential of $5 \alpha 3 \alpha$-THPROG observed by Wang et al. (2010) in a mouse model of Alzheimer's disease may also reduce the depressive-like behaviors and cognitive deficits associated with prolonged chronic stress exposure. The ability of neurosteroids to increase cell proliferation and to restore corticolimbic network function may contribute to the putative antidepressant actions of certain steroids (Uzunova et al., 1998). Of interest, in patients suffering from Alzheimer's disease the levels of the endogenous neurosteroid $5 \alpha 3 \alpha$-THPROG are reduced throughout the brain, but particularly in stress-related brain structures such as the hippocampus, amygdala, hypothalamus, and frontal cortex (Weill-Engerer et al., 2002). Furthermore, although CRH induced an increase in plasma $5 \alpha 3 \alpha$-THPROG in patients suffering from Alzheimer's disease, the neurosteroid levels remained significantly lower than in control patients (Bernardi et al., 2000). Therefore, it is conceivable that neurosteroids may be less effective in mediating the physiological responses to stress in patients suffering from this disease and restoration of normal levels may prove therapeutically beneficial.

Chronic stress exposure not only induces remodeling of dendritic architecture, but additionally alters synapse formation and the expression of various neurotransmitter receptors (Joels et al., 2007; McEwen, 2010). Given that endogenous neurosteroids, such as $5 \alpha 3 \alpha$-THPROG and $5 \alpha 3 \alpha$-THDOC, are such potent positive allosteric modulators of $\mathrm{GABA}_{\mathrm{A}} \mathrm{R}$ function, and that $\mathrm{GABA}_{\mathrm{A}} \mathrm{Rs}$ have such a prominent influence on the HPA axis, the impact that chronic stress has upon $\mathrm{GABA}_{\mathrm{A}} \mathrm{R}$-mediated inhibition within the brain is of particular interest. The majority of research has focused upon chronic stress-induced alterations in the excitatory neurotransmitter systems, with relatively little attention being given to the GABAergic system. However, the expression of mRNAs encoding for certain $G_{A B A} R$ subunits was altered in the rat hippocampus following the chronic exposure to levels of corticosterone achieved during stress (Orchinik et al., 1995), although the functional significance of this altered expression remains unexplored. The impact that stress has upon brain function (e.g., LTP) is dependent upon the level of glucocorticoid elevation and the duration of the stressor exposure, in addition to the brain region under consideration (Lupien et al., 2009). Nevertheless, in chronically stressed rats, hippocampal LTP is difficult to evoke (Alfarez et al., 2003) and this scenario can be mimicked in control non-stressed animals by the activation of glucocorticoid receptors (GRs), i.e., following $20 \mathrm{~min}$ pre-incubation of hippocampal slices in corticosterone (100 nM; Alfarez et al., 2002). Whether this effect of chronic stress is associated with an altered expression of $G_{A B A} R$ Rs as recently described for the hippocampus and mPFC of Alzheimer's patients (Rissman et al., 2007; Luchetti et al., 2011), is not known. 
At the level of the PVN, chronic variable stress significantly increases the number of glutamatergic and noradrenergic terminals apposing $\mathrm{CRH}$-immunopositive cell bodies and dendrites, whilst having no effect upon the number of GABAergic terminals (Flak et al., 2009). Thus, the balance between excitatory and inhibitory control of the HPA axis appears significantly altered following chronic stress exposure. Although the number of GABAergic terminals apposing parvocellular neurons was unchanged, a marked down-regulation of the $\beta 1$ and $\beta 3 \mathrm{GABA}_{\mathrm{A}} \mathrm{R}$ subunits was observed following chronic variable stress (Cullinan and Wolfe, 2000). This effect may indirectly modulate the neurosteroid sensitivity of these receptors (Fancsik et al., 2000; Brussaard and Koksma, 2003; Harney et al., 2003) via documented kinasespecific interactions with $\beta$ subunit isoforms (Kittler and Moss, 2003). Electrophysiological recordings from parvocellular neurons derived from rats exposed to chronic variable stress revealed a reduction in the frequency of mIPSCs, supporting the notion of reduced GABAergic inhibition of these neurons (Verkuyl et al., 2004). However, in contrast to the morphological data, a reduction in the MIPSC frequency with no change to the paired pulse ratio would suggest a reduction in the number of GABAergic synapses apposing these neurons (Verkuyl et al., 2004). Clearly, the impact that these alterations in $\mathrm{GABA}_{\mathrm{A}} \mathrm{R}$ expression in stress-sensitive brain structures have upon neurosteroid modulation of the stress response deserves further investigation.

A number of preclinical and clinical studies have implicated $5 \alpha 3 \alpha$-THPROG and other $3 \alpha$-reduced neurosteroids in depression and attributed the anxiolytic properties of some antidepressants of the selective serotonin reuptake inhibitors (SSRI) class (e.g., fluoxetine or $\left.\operatorname{Prozac}^{\circledR}\right)$ to these endogenous neuromodulators (Guidotti and Costa, 1998; Eser et al., 2006; Uzunova et al., 2006). In support, the brain levels of $5 \alpha 3 \alpha$-THPROG are significantly decreased in animal models of depression or PTSD (Serra et al., 2000, 2008; Pinna, 2010) and similarly the levels of this neurosteroid are also reduced in the plasma and CSF of depressed patients (Romeo et al., 1998; Uzunova et al., 1998). In addition, treatment with exogenous neurosteroids produces robust antidepressant-like actions in rodent models of depression (Pinna et al., 2009), while in humans elevated $5 \alpha 3 \alpha$-THPROG levels have been associated with a reduction in depressive behavior (reviewed in Uzunova et al., 2006). Intriguingly, animal studies have revealed that acute treatment with the SSRI fluoxetine normalizes the brain levels of $5 \alpha 3 \alpha$-THPROG in a stereospecific manner (Uzunov et al., 1996; Matsumoto et al., 1999; Serra et al., 2001; Pinna et al., 2004; Figure 1). Similarly, the CSF levels of this neurosteroid are also restored in depressed patients following SSRI treatment (Romeo et al., 1998; Uzunova et al., 1998). The fluoxetine-induced increase in neurosteroid levels occurs at concentrations significantly lower than those required to block serotonin reuptake and on a faster time scale (i.e., $\sim 30 \mathrm{~min}$ ) than that associated with the clinical improvement by classical antidepressants (i.e., 3 weeks; Uzunov et al., 1996; Guidotti and Costa, 1998; Pinna et al., 2004). Therefore, enhancement of $\mathrm{GABA}_{\mathrm{A}} \mathrm{R}$-mediated inhibition may contribute to the anxiolytic actions of this SSRI (Longone et al., 2008). Fluoxetine has been postulated to increase the levels of $5 \alpha 3 \alpha$-THPROG by either potentiating the reduction of $5 \alpha$-DHP, or by inhibiting the oxidation of $5 \alpha 3 \alpha$-THPROG back to $5 \alpha$-DHP, possibly via the modulation of $3 \alpha-H S D$ activity (Uzunov et al., 1996). In support, Griffin and Mellon (1999) reported that fluoxetine and other SSRIs (e.g., paroxetine) enhanced the reductive function of recombinant rat and human forms of $3 \alpha$-HSD. However, a direct interaction of SSRIs with $3 \alpha$-HSD remains controversial as a subsequent study did not support these findings (Trauger et al., 2002).

Plasma and CSF levels of neurosteroids measured in clinical studies may not accurately reflect their brain levels, particularly if such steroids are acting in a paracrine or autocrine manner. Consequently, determining whether alterations in neurosteroid levels following SSRI treatment reduce depressive behaviors has proved difficult. However, a number of non-pharmacological antidepressant treatments, including electroconvulsive therapy (ECT) and repetitive transcranial magnetic stimulation (rTMS), all failed to alter the levels of $5 \alpha 3 \alpha$-THPROG, although they produced clinical improvement of patients suffering from major depression (Padberg et al., 2002; Baghai et al., 2005). Moreover, although partial sleep deprivation (PSD) ameliorated symptoms in $60 \%$ of patients suffering from major depression, the concentrations of neurosteroids were not affected by PSD in either responders or non-responders (Schule et al., 2003). Similarly, responders and non-responders to treatment with the antidepressant mirtazapine exhibited similar neurosteroids levels (Schule et al., 2006). Collectively, although a dysregulation of neurosteroid equilibrium has been consistently reported in animal models and in humans suffering from depression, it remains unclear whether the normalization of neurosteroid levels following fluoxetine treatment is actively involved in alleviating depressive symptoms, or is simply a pharmacological by-product associated with clinical improvement, i.e., changes in neurosteroid production may reflect distinct properties of certain antidepressants rather then alleviation of mood symptoms (Uzunova et al., 2006).

\section{PROGRAMMING OF THE STRESS RESPONSE: A ROLE FOR NEUROSTEROIDS?}

The maturation of the HPA axis is highly sensitive to prenatal and postnatal stress, resulting in adverse alterations in the behavioral and neuroendocrine responses to stress in adulthood. In the accompanying section we will consider specifically the role of neurosteroids in animal models of prenatal and postnatal stress and their potential relevance to the etiology of stressassociated pathologies, e.g., depression, Alzheimer's disease, and drug addiction.

\section{PRENATAL STRESS}

Exposure of the fetal brain to stress, or glucocorticoids, can influence the development of physiological systems resulting in an increased susceptibility in adulthood to cardiovascular (Barker, 2002), metabolic (Levitt et al., 2000), and affective disorders (Welberg and Seckl, 2001). Indeed, the exposure of pregnant rats (gestation day 14, G14) to chronic restraint stress resulted in offspring that displayed an anxious-like phenotype both as neonates (P7) and adults. Intriguingly, these behavioral effects of prenatal stress (PNS) were attenuated by the concomitant administration of $5 \alpha 3 \alpha$-THPROG to the pregnant dams (G14; Zimmerberg and Blaskey, 1998). Similarly, Brunton and Russell have explored a putative role for neurosteroids in a model of social PNS (social 
defeat of a female rat during the last week of pregnancy by a resident lactating rat). In this model, both male and female adult offspring displayed exaggerated adrenocorticotropic hormone (ACTH) and corticosterone responses to an acute stress challenge, i.e., interleukin-1 $\beta$ (IL-1 $\beta$ ) administration (Brunton and Russell, 2010). Interestingly, prior treatment ( 2 and $20 \mathrm{~h}$ before the IL- $1 \beta$ challenge) with $5 \alpha 3 \alpha$-THPROG normalized the exaggerated (approximately threefold) ACTH response in female, but not male adult rats exposed prenatally (i.e., during the last week of pregnancy) to social PNS (Brunton and Russell, 2011). However, the testosterone metabolite androstanediol, which also enhances $\mathrm{GABA}_{\mathrm{A}} \mathrm{R}$ function (Gee et al., 1988; Reddy and Jian, 2010), normalized the HPA response to IL- $1 \beta$ of male PNS rats (Brunton and Russell, 2011). These observations are consistent with the proposal that neurosteroidogenesis may be compromised in the adult brain of rats exposed to PNS. Yet, the mechanism whereby these neurosteroids restore the neuroendocrine response to IL-1 $\beta$ administration is currently unclear, although given the prominent role of $\mathrm{GABA}_{\mathrm{A}} \mathrm{R}$-mediated inhibition in the stress neurocircuitry (Cullinan et al., 2008), potentiation of $\mathrm{GABA}_{\mathrm{A}} \mathrm{R}$ function is likely to contribute. For example, neurosteroid administration to PNS adult rats may restore HPA sensitivity through a mechanism similar to that previously described in dams during the final stage of pregnancy (Brunton et al., 2009). Thus, during late pregnancy (pregnancy day 21), the maternal response to an IL-1 $\beta$ challenge is reduced due to the inhibition of noradrenergic inputs to the PVN. This effect appears consequent to an increased expression of enkephalin and presynaptic $\mu$-opioid receptors, an adaptation that is critically dependent on $5 \alpha 3 \alpha$-THPROG (Brunton et al., 2009). An attractive possibility worthy of investigation is that neurosteroids such as $5 \alpha 3 \alpha$-THPROG and androstanediol may induce similar adaptations in adult PNS rats to normalize the endocrine response to IL-1 $\beta$ administration (see Brunton and Russell, 2011). While the specific mechanism whereby $5 \alpha 3 \alpha$-THPROG induces increased enkephalin and opioid receptor expression in pregnant rats remains to be elucidated, the "glucocorticoid-like" effects of neurosteroids upon $\mathrm{CRH}$ and vasopressin (AVP) expression within the PVN (Patchev et al., 1994, 1996) and the modulation of PVN neuropeptide expression by GABA $\mathrm{A}$ Rs (Cole and Sawchenko, 2002; Bali and Kovacs, 2003) warrant further investigation. Of further note, the fetal neuroprotective actions of $5 \alpha 3 \alpha$-THPROG may not be exclusively associated with direct effects within the fetal brain, as elevated maternal levels of this neurosteroid during the latter stages of pregnancy act to reduce the sensitivity of maternal HPA axis to stressful challenges, and hence, the exposure of the fetus to maternally derived glucocorticoids (reviewed in Brunton and Russell, 2008).

Perturbations in neurosteroid levels have also been reported in the fetal brain following an acute hypoxic challenge induced by constriction of the umbilical cord, a response, which may result from increased $5 \alpha$-reductase and cytochrome $\mathrm{P} 450_{\text {scc }}$ expression within the brain (Nguyen et al., 2004). The observed elevation in central neurosteroid levels in response to hypoxia may represent an endogenous neuroprotective mechanism in the developing brain. In agreement, binding studies, using $\left[{ }^{35} \mathrm{~S}\right] \mathrm{TBPS}$ have revealed that by late gestation $\mathrm{GABA}_{\mathrm{A}} \mathrm{Rs}$ are significantly more sensitive to $5 \alpha 3 \alpha$-THPROG modulation than in the adult brain
(Crossley et al., 2000). In contrast, exposure to chronic hypoxic stress (induced through the injection of inert microspheres into the fetal circulation) increased the expression of the neurosteroid synthesizing enzyme $5 \alpha$-reductase in most brain regions, but had no effect upon the amount of $5 \alpha 3 \alpha$-THPROG in the fetal brain after 20 days of hypoxemia (Nguyen et al., 2003). The reduced capacity of the fetus to synthesize $5 \alpha 3 \alpha$-THPROG in response to a chronic hypoxic challenge may result from a reduction in the supply of maternally derived $5 \alpha 3 \alpha$-THPROG and/or the impaired metabolism of progesterone to other neurosteroid precursors. However, the ability of the fetal brain to synthesize other neuroactive steroids and the impact that acute and chronic stress have upon this remains unknown. Collectively, these observations suggest that neurosteroids such as $5 \alpha 3 \alpha$-THPROG may be important neuroprotective agents within the fetal brain (reviewed in Hirst et al., 2009). In this context, it is conceivable that the documented excitatory and trophic actions of GABA in the prenatal CNS (Represa and Ben-Ari, 2005) are not incidental to the neuroprotective actions of neurosteroids. However, it should be noted that the excitatory actions of GABA, observed during development have also been associated with neuronal damage (e.g., epilepsy-see Dzhala et al., 2005).

Few studies have measured changes in brain function associated with PNS in humans. However, children of mothers who during pregnancy experienced stress, depression, or anxiety, or who were treated with glucocorticoids, exhibit increased basal HPA activity, thus indicating that there are long-lasting alterations affecting the child's normal development of the stress response (reviewed in Lupien et al., 2009). This altered HPA programming may contribute to the increased vulnerability of the progeny to affective disorders in later life (Bale et al., 2010).

\section{POSTNATAL STRESS}

Endogenous neurosteroids have also been implicated in the postnatal maturation of the HPA axis. The early postnatal period is crucial in the development and maturation of the HPA axis and is characterized in rodents, by a period (PN4-14) of marked hyporesponsivity (Sapolsky and Meaney, 1986). As this period coincides with stages of axonal growth, synaptogenesis, and myelination of key brain circuits, it has been postulated that this hyporesponsive phenotype protects the developing brain from excessive glucocorticoid exposure. Adverse early life events are known to result in profound and long-lasting alterations in the mature organism's behavioral and neuroendocrine response to stress (Francis and Meaney, 1999). Specifically, the mother-pup interaction has been shown to strongly influence the maturation of the stress neurocircuitry, as both in rodents and in primates reduced maternal care is associated with impaired behavioral and neuroendocrine responses to stress in adulthood (Sanchez et al., 2001). Conversely, enhanced maternal care increases the ability to cope with stressful experiences in later life (Francis et al., 1999).

Suggesting a possible role for neurosteroids in the programming of the stress response, $5 \alpha 3 \alpha$-THPROG reduced the number of ultrasonic vocalizations (USVs), a measure of an anxious-like phenotype, in neonatal (PN7) rat pups previously exposed to maternal separation (Zimmerberg et al., 1994, 1999), while maternally separated (between PN 2 and 7) neonatal rats displayed a 
reduction in the number of USVs compared to non-stressed controls when exposed to a subsequent maternal separation at PN8 (Zimmerberg et al., 1999). Interestingly, the adaptation exhibited by maternally separated pups to a subsequent separation correlated with enhanced $5 \alpha 3 \alpha$-THPROG levels in the brain following maternal separation (Kehoe et al., 2000). Thus, it is tempting to speculate that neurosteroid-induced enhancement of GABAergic inhibition may contribute to this hyporesponsive phenotype. However, maternally separated rats exhibited a more anxious phenotype in response to a novel stressor than their non-stressed counterparts (Patchev et al., 1997; Zimmerberg et al., 1999). Moreover, for adult rats that have been maternally separated (PN 2-10) mRNA levels of CRH and GR mRNA were increased and decreased in the PVN and the hippocampus, respectively. Interestingly, these behavioral and neuroendocrine alterations were attenuated when $5 \alpha 3 \alpha$-THDOC was concomitantly administered during maternal separation, suggesting that these $5 \alpha$-reduced neurosteroids may exert persistent stress-protective effects during development (Patchev et al., 1997). Intriguingly, the level of $3 \alpha$-HSD mRNA has been shown to be elevated in the dentate gyrus of male and female rats at P7, a time coinciding with the stress hyporesponsive period, further supporting a physiological role for endogenous neurosteroids at this stage of development (Mitev et al., 2003). Behavioral and neuroendocrine dysregulation induced by neonatal maternal separation exhibits differences between genders (Mitev et al., 2003), although such effects may be additionally dependent on the maternal separation protocol utilized (Zimmerberg and Kajunski, 2004). Thus, adult male, but not female rats that experienced maternal separation (PN 5-10) exhibited a more anxious-like phenotype on the EPM than their non-stressed counterparts (Mitev et al., 2003). However, ovariectomized (OVX) female rats exposed to maternal separation in infancy exhibited an anxious-like phenotype on the EPM in adulthood $c f$ control females, suggesting that peripheral steroids may normally mask the behavioral consequences of neonatal stress in females. Moreover, the concomitant administration of $5 \alpha 3 \alpha$-THPROG during maternal separation counteracted the behavioral and neuroendocrine consequences of neonatal stress in both genders (Mitev et al., 2003).

Supporting the notion that abnormal $\mathrm{GABA}_{\mathrm{A}} \mathrm{R}$ function is associated with exposure to early life adversities, early life stress induces changes to the expression of $\mathrm{GABA}_{\mathrm{A}} \mathrm{Rs}$ that occur concomitantly with the perturbations of behavior and neuroendocrine function described above. These changes in expression are evident in brain regions that are important for the processing of "psychogenic" stressors, a function known to be significantly altered in adulthood by early life stress (Caldji et al., 2003). In general, offspring receiving good quality maternal care displayed significantly greater mRNA expression of $\alpha 1$ and $\beta 3$-subunits in limbic and forebrain regions in comparison to those that received low quality maternal care (Caldji et al., 2003). Intriguingly, the majority of changes observed in $\mathrm{GABA}_{\mathrm{A}} \mathrm{R}$ subunit expression appeared to be unique to the amygdala, a region important in the development of fear-related memory (Ehrlich et al., 2009; Roozendaal et al., 2009). Thus, in the central (CeA), basolateral (BLA), and lateral (LA) amygdaloid nuclei, adult offspring that had experienced high-quality maternal care expressed significantly greater mRNA levels of both $\gamma 1$ and $\gamma 2$-subunits, the latter being important in mediating the majority of actions of benzodiazepines. However, in the central and basolateral regions of the amygdaloid nucleus, low-maternal care offspring exhibited relatively greater levels of $\alpha 3$ and $\alpha 4$ mRNA (Caldji et al., 2003). How these changes in the levels of subunit mRNAs translate to perturbations of synaptic/extrasynaptic inhibition, or to changes in the sensitivity of native $\mathrm{GABA}_{\mathrm{A}}$ Rs to neurosteroid modulation provides scope for future investigations.

Changes in $\mathrm{GABA}_{\mathrm{A}} \mathrm{R}$ subunit expression may also be associated with altered localization of GABAergic interneurons in a manner similar to that described by Grobin et al. (2003) for the prefrontal cortex following elevated levels of neurosteroids during development. Such a scenario in the amygdala, hippocampus, and prefrontal cortex may severely compromise the ability of an organism to process and cope with a variety of stressors. In this regard, it would be of interest to investigate whether the quality of maternal care influences neurosteroids levels and their actions in the developing brain. The proposal that extrasynaptic $\delta-G A B A_{A} R s$ may mediate some of the physiological actions of neurosteroids may be relevant in this respect (Maguire and Mody, 2009). Thus, a recent study has indicated maternal care to be compromised in mice lacking the $\delta$ subunit $\left(\delta^{0 / 0}\right.$ mice - Maguire and Mody, 2008). Moreover, genetic inactivation of this subunit blunts the anxiolytic actions of neurosteroids in an acute stress challenge paradigm in adult mice (Mihalek et al., 1999). Collectively, these findings raise the intriguing prospect that early life stress may encode long-lasting changes in network function, contributing to the loss of the anxiolytic action of neurosteroids in adult $\delta^{0 / 0}$ mice. Consistent with this suggestion, the output of neuroendocrine parvocellular neurons of the hypothalamic PVN is insensitive to the inhibitory actions of the neurosteroid $5 \alpha 3 \alpha$-THPROG in neonatal (PN18-P24) mice lacking the $\delta$ subunit $c f$ wild type counterparts (Gunn et al., 2010). However, complicating the interpretation of these findings, $\delta$-GABA $\mathrm{R}$ are not expressed in the PVN (Wisden et al., 1992; Gunn et al., 2010). This observation suggests that these receptors are unlikely to be the direct molecular target of $5 \alpha 3 \alpha-$ THPROG within the PVN and caution should be exercised when directly implicating $\delta$-GABA $\mathrm{A}$ s in the actions of neurosteroids based upon $\delta$ "knock out" studies.

In contrast to long periods of maternal separation, short episodes $(\sim 15 \mathrm{~min})$ induce a neuroendocrine plasticity that is characterized by reduced stress responses (Plotsky and Meaney, 1993; Avishai-Eliner et al., 2001), enhanced resilience to depressive behaviors (Meaney et al., 1991), and improved learning and memory function (Fenoglio et al., 2005). Augmented maternal care in the early postnatal period (PN 2-P8), results in reduced levels of $\mathrm{CRH}$ expression within the PVN during adulthood. Interestingly, this effect was associated with a reduction in glutamatergic innervation of neuroendocrine parvocellular neurons during postnatal development and the increased expression of the transcription repressor neuron-restrictive silencer factor (NRSF), an adaptation maintained through to adulthood (Korosi et al., 2010). Thus, the reduced glutamatergic excitation in the postnatally developing PVN may be important in initiating the reprogramming of CRH expression, possibly via the induction of genomic and epigenetic modifications, which, in turn, would result in increased stress resilience in later life (Korosi et al., 2010). Whether limbic 
and forebrain stress centers exhibit similar adaptations deserves further investigation as alterations in the neuronal architecture of these brain structures could significantly amplify individual stress vulnerability, or resilience. Moreover, epigenetic adaptations resulting from specific mother-pup interactions have the potential to be transmitted across subsequent generations to impact on their susceptibility to stress exposure (Weaver et al., 2004; Tsankova et al., 2007; Murgatroyd et al., 2009; Brunton and Russell, 2011; Curley et al., 2011).

In agreement with animal models of postnatal stress, studies in human subjects have revealed that early stress has a significant negative impact upon brain development and function in children, which may predispose individuals to develop affective disorders in adulthood (reviewed in Repetti et al., 2002; McEwen, 2003). Specifically, the timing and severity of early life stress has been postulated to induce pathophysiological alterations within the CNS that increases the stress vulnerability of individuals, predisposing them to psychiatric disorders in later life (McGowan et al., 2009; Neigh et al., 2009). Consistent with this proposal, epigenetic reductions in hippocampal glucocorticoid feedback have been associated with childhood abuse and increased risk of suicide (McGowan et al., 2009), an effect that is analogous to alterations in hippocampal GR expression in rats exposed to low quality of maternal care (Weaver et al., 2004).

Whether in humans early life stress induces alterations of neurosteroid levels, similar to those described for a variety of animal models is currently not known, but if so they may be of pathological relevance. Indeed, normalization of such levels may be therapeutically beneficial in a manner similar to that reported for depressed patients (Uzunov et al., 1996). In this respect, the recent demonstration that XBD173 stimulates the synthesis of $\mathrm{GABA}_{\mathrm{A}} \mathrm{R}$-active steroids and in humans this drug acts as an effective anxiolytic, suggests that novel therapeutic strategies for the treatment of early stress-related disturbances may be possible (Rupprecht et al., 2009).

\section{REGULATION OF NEUROSTEROID SYNTHESIZING ENZYMES; A ROLE FOR GLUCOCORTICOIDS AND NEUROPEPTIDES?}

Although acute stress rapidly elevates brain neurosteroid levels in rodents (Purdy et al., 1991), the mechanism(s) by which a stressor induces neurosteroidogenesis is currently unknown. Indeed, relatively little is known regarding the mechanisms responsible for regulating the activity of steroid synthesizing enzymes and transporters such as TSPO, $5 \alpha$-reductase, and $3 \alpha$-HSD within the CNS. However, a recent study indicates that NMDA receptor activation can rapidly (within $5 \mathrm{~min}$ ) increase the levels of neurosteroids in hippocampal CA1 neurons (Tokuda et al., 2011), possibly signaling via p38 mitogen-activated protein kinase (MAPK), neuronal nitric oxide synthase (nNOS), and calcineurin (Izumi et al., 2008; Figure 1). Additionally, certain steroid hormones, e.g., corticosterone and estrogen, as well as the neuropeptide CRH, can modulate the levels of endogenous neurosteroids in a gender and steroid-specific manner (Torres et al., 2001; Mitev et al., 2003). For example, Mitev et al. (2003) have reported corticosterone to increase $3 \alpha$-HSD expression in both genders. In contrast, progesterone, a precursor of $5 \alpha 3 \alpha$-THPROG had no effect upon $3 \alpha$-HSD expression in either gender, indicating that the activity of $3 \alpha$-HSD is not simply correlated with substrate levels. These observations suggest that following stress exposure, the resultant elevated corticosterone levels may increase $3 \alpha$-HSD expression and consequently, increase the levels of neurosteroids probably via classical genomic mechanisms. However, glucocorticoids can additionally exert rapid, non-genomic effects in a number of stress-related brain structures (Tasker and Herman, 2011), and such actions may contribute to curtailing HPA activity (Tasker and Herman, 2011). The molecular mechanism of rapid glucocorticoid signaling, and the impact of this steroid hormone upon neuronal excitability appears to be brain region, neuron, and even synapse specific (Di et al., 2003, 2005, 2009; Karst et al., 2005, 2010; Tasker and Herman, 2011). For example, in magnocellular neurons of the supraoptic nucleus (SON) and PVN, glucocorticoids activated divergent Gprotein signaling pathways to inhibit and increase the release of glutamate and GABA respectively, in a synapse-specific manner (Di et al., 2009). Glucocorticoid-induced endocannabinoid synthesis and retrograde signaling specifically inhibited glutamate release, while an enhanced GABA release has been associated with the rapid stimulation of nitric oxide (NO) synthesis (Di et al., 2009). Rapid glucocorticoid effects are dependent upon G-protein and protein kinase activation as endocannabinoid synthesis results from $\mathrm{G}_{\alpha \mathrm{s}}$-induced production of cAMP and the subsequent activation of PKA, whereas the activated $\mathrm{G}_{\beta \gamma}$ dimer leads to activation of nNOS and NO synthesis. Whether such signaling pathways can stimulate neurosteroidogenesis is currently unknown, although the recent report that NMDA receptor activation stimulated neurosteroidogenesis via similar downstream signaling pathways (i.e., MAPK, nNOS; Tokuda et al., 2011) suggests the possibility of an analogous scenario (Figure 1). Furthermore, it is plausible that the impact of an NO-induced increase in GABA release upon the inhibitory tone exerted on hypothalamic magnocellular neurons could be further amplified by neurosteroid potentiation of $\mathrm{GABA}_{\mathrm{A}} \mathrm{R}$ function. Indeed, neurosteroids, such as $5 \alpha 3 \alpha$-THPROG, acting at presynaptic $\mathrm{GABA}_{\mathrm{A}} \mathrm{Rs}$, typically cause an increase in synaptic transmission (Haage et al., 2002; Uchida et al., 2002; Ruiz et al., 2010) due to the excitatory actions of GABA on presynaptic terminals (Kullmann et al., 2005; Szabadics et al., 2006; Trigo et al., 2008). Thus, following a stressful challenge, locally produced neurosteroids may potentially modulate synaptic transmission via actions at both pre- and postsynaptic $\mathrm{GABA}_{\mathrm{A}} \mathrm{Rs}$ (Figure 2C).

Intriguingly, in rodents both $\mathrm{CRH}$ and $\mathrm{ACTH}$ elevate the brain and plasma levels of $5 \alpha 3 \alpha$-THPROG (Torres et al., 2001). Similarly, in humans plasma levels of this neurosteroid were elevated following CRH administration (Bernardi et al., 2000). These observations are consistent with the proposal that neurosteroids may be implicated in curtailing HPA axis activity. Although it is unclear whether $\mathrm{CRH}$ directly stimulates neurosteroid synthesis (see below on Neurosteroids and Ethanol), a growing body of evidence indicates that $\mathrm{CRH}$ and its related peptides (i.e., the urocortins) have extra-hypothalamic molecular targets and, for example, may modulate synaptic transmission in stress-sensitive regions such as the CeA, mPFC, and BST (Swanson et al., 1983; Bale and Vale, 2004; Gallagher et al., 2008). Thus, it is conceivable that $\mathrm{CRH}$-induced neurosteroidogenesis may influence neurotransmission in a number of limbic and 
forebrain structures that are important for the processing of stressor information. Moreover, the notion of a physiological role for $\mathrm{CRH}$-induced neurosteroidogenesis is further supported by the observation that downstream G-protein coupled signaling pathways (e.g., MAPK) associated with activation of CRH systems have already been implicated in neurosteroidogenesis (Tokuda et al., 2011; Figure 1).

Interestingly, the dendritic release of various neuropeptides within the hypothalamus has been proposed as an important mechanism in the functional reorganization of neuronal networks (Ludwig and Leng, 2006) and may be involved in the coupling of the hypothalamic neurohypophysial system and the HPA axis during periods of stress (Engelmann et al., 2004). It is conceivable that other neuropeptides such as oxytocin, AVP, and neuropeptide Y (NPY), are similarly capable of stimulating or, indeed, inhibiting neurosteroid synthesis. How these neuromodulators may influence the coupling of neuronal networks thus warrants further investigation.

Neuropeptides may not only influence the de novo synthesis of $3 \alpha$-reduced steroids, but can additionally dynamically modulate the neurosteroid sensitivity of $\mathrm{GABA}_{\mathrm{A}}$ Rs by changing the phosphorylation state of the receptor, or associated proteins. For example, in magnocellular neurons of the SON, synaptic GABA $\mathrm{Rs}$, while steroid-sensitive during pregnancy, become insensitive to $5 \alpha 3 \alpha$-THPROG $24 \mathrm{~h}$ after parturition (Brussaard et al., 1997). This dynamic shift in the pharmacology of the receptor, appeared to be caused by an oxytocin-induced change in the relative activity of endogenous phosphatases and PKC, acting to blunt the sensitivity of $\mathrm{GABA}_{\mathrm{A}}$ Rs to the progesterone metabolite (Koksma et al., 2003). Given that neuropeptide receptors share similar G-protein coupled signaling pathways, CRH, NPY, and AVP also have the potential to modulate $\mathrm{GABA}_{\mathrm{A}} \mathrm{R}$ neurosteroid sensitivity. The physiological significance of such a scenario has not been explored, although such studies will be complex as the impact of phosphorylation upon neurosteroid sensitivity of $\mathrm{GABA}_{\mathrm{A}}$ Rs is both kinase and neuronspecific (Fancsik et al., 2000; Brussaard and Koksma, 2003; Harney et al., 2003).

\section{NEUROPEPTIDES, NEUROSTEROIDS, AND REWARD PATHWAYS}

There may be a reciprocal relationship between processing stress and reward information within the brain, as several common brain structures are critically involved in their regulation. Thus, for example, the extended amygdala [comprising the BST, the CeA, and the posterior nucleus accumbens (NAc) shell], may mediate many of the motivational effects of opposing processes (i.e., the hedonic positive and negative emotional states that occur at different stages of drug taking), associated with drug dependence (Koob and Le Moal, 2001). Interestingly, as noted above, the BST influences HPA activity via projections to the PVN and appears to be an important structure involved in the integration of stressrelated information originating in limbic and forebrain inputs (Ulrich-Lai and Herman, 2009). In animal models, acute administration of drugs of abuse causes activation of the HPA axis, an effect believed to facilitate drug reward by enhancing the activity of brain motivational circuits, resulting in the acquisition of drugseeking behavior (reviewed in Koob, 2008). In contrast, the HPA response to drugs of abuse becomes blunted following repeated administration (Rasmussen et al., 2000; Semba et al., 2004), as high levels of glucocorticoids may feedback to negatively regulate the HPA axis (de Kloet et al., 2005; Koob, 2008). Additionally, elevated glucocorticoid levels associated with repeated HPA axis activation can "sensitize" extra-hypothalamic CRH systems (e.g., CeA) and norepinephrine (NE) systems in the BLA, known to be involved in behavioral responses to stressor exposure (Swanson and Simmons, 1989; Imaki et al., 1991; Makino et al., 1994). As activation of these extra-hypothalamic stress-sensitive targets characterizes the withdrawal/negative affect stage of addiction, their dysregulation may underpin at least some of the behavioral responses associated with chronic drug treatment and withdrawal (Koob and Kreek, 2007; Koob and Zorrilla, 2010). In agreement, substantial evidence indicates that extra-hypothalamic CRH systems are activated during the development of dependence from ethanol and other drugs of abuse (Koob, 2008). Furthermore, a number of other anxiogenic (e.g., NE, dynorphin, orexin, AVP) and anxiolytic (NPY) neuropeptides have similarly been associated with the transition to, and maintenance of, drug dependence (reviewed in Koob, 2008).

As $\mathrm{CRH}$ administration induces an increase in the brain levels of $5 \alpha 3 \alpha$-THPROG, endogenous neurosteroids may not only be involved in regulating the activity of the HPA axis, but, given the close association of the stress and reward systems, they may additionally act as important modulators of the reward circuitry. Indirect support for a close association between stress and reward systems, comes from the clinical studies of drug addiction and major depression. Thus, Enoch et al. (2010) have recently reported an increased propensity particularly to cocaine addiction to segregate with specific polymorphisms of the $\mathrm{GABA}_{\mathrm{A}} \mathrm{R} \alpha 2$ subunit only when associated with a previous history of early life stress. Further, deep brain stimulation of the NAc significantly improved clinical ratings of anhedonia, an inability to gain pleasure from previously pleasurable activities, in patients suffering from forms of depression resistant to pharmacological treatment (Schlaepfer et al., 2008) thus, suggesting a dysfunction of the reward circuitry. Interestingly, $5 \alpha$-reductase is present in the NAc and the expression of this enzyme is known to be sensitive to acute stress (i.e., swim stress) in the mPFC (Sánchez et al., 2008) and to early chronic psychosocial stress in both the mPFC and NAc (Bortolato et al., 2011), suggesting that it may play a physiological role in both brain regions (Bortolato et al., 2011). In support, $5 \alpha 3 \alpha$-THPROG influences dopamine efflux in the NAc (Motzo et al., 1996; Rouge-Pont et al., 2002). Furthermore, the systemic administration and intraaccumbal infusion of $5 \alpha 3 \alpha$-THPROG in OVX rats significantly reduced the immobility time in the forced swim test, an animal model of depression (Molina-Hernandez et al., 2005).

Collectively, these findings are consistent with the proposal that the NAc may be an important site in mediating the putative antidepressant actions of neurosteroids. Moreover, the stressprotective actions of neurosteroids may contribute to such an effect as the NAc innervates several important stress-related brain structures including the BST, mPFC, BLA, in addition to several hypothalamic nuclei (Ulrich-Lai and Herman, 2009).

A significant body of work has investigated a possible relationship between neurosteroids acting at the $\mathrm{GABA}_{\mathrm{A}} \mathrm{R}$ and ethanol. 
Thus, in the final section we will specifically focus on the putative role of neurosteroids in the actions of alcohol.

\section{ETHANOL AND NEUROSTEROIDS}

Neurosteroids have been proposed as important mediators of ethanol sensitivity and dysregulation of ethanol-induced neurosteroidogenesis has been associated with an increased risk of alcoholism (Morrow et al., 2006). Thus, a number of studies have indicated that increased neurosteroidogenesis within the brain contributes to some of the behavioral and electrophysiological actions associated with ethanol administration (VanDoren et al., 2000; Khisti et al., 2003; Sanna et al., 2004; Morrow et al., 2006; Izumi et al., 2007; Boyd et al., 2010; Figure 1). For example, acute ethanol treatment in CA1 pyramidal cells has been reported to stimulate neurosteroid synthesis, resulting in an increase in the peak amplitude and a prolongation of the decay time course of mIPSCs recorded from these neurons (Sanna et al., 2004). Moreover, acute ethanol $(60 \mathrm{mM})$ completely blocked LTP in rat hippocampal slices, an effect attenuated by inhibition of $5 \alpha-$ reductase by finasteride, or by the neurosteroid sequestering agent, $\gamma$-cyclodextrin (Izumi et al., 2007; Tokuda et al., 2011). These observations implicate neurosteroidogenesis in the suppression of LTP by ethanol. Additionally, acute ethanol application increases the frequency of mIPSCs recorded from CA1 pyramidal neurons. However, in contrast to the ethanol effect upon mIPSC kinetics, this action is not mimicked by a neurosteroid precursor (progesterone) or by CP34 a TSPO "agonist," suggesting this apparent presynaptic effect of ethanol to be independent of neurosteroid production (Sanna et al., 2004). A similar presynaptic effect of ethanol occurs in the cerebellum (Carta et al., 2004) and amygdala (Roberto et al., 2003; Nie et al., 2004). Interestingly, in the latter this effect appears to be mediated by the activation of $\mathrm{CRH}$ receptor 1 (CRH R1; Nie et al., 2004).

A role for CRH in ethanol actions is consistent with evidence from animal models demonstrating the activation of extrahypothalamic CRH systems in the development of alcohol dependence (Heilig and Koob, 2007; Koob, 2008), although whether the effects of ethanol in the hippocampus involve CRH is not known. As noted above, CRH also increases neurosteroid levels, although the specific mechanisms underpinning such an action are not fully elucidated (Torres et al., 2001). Interestingly, PKC, and in particular the PKCE isoform, appears to be an important mediator of $\mathrm{CRH}$ and ethanol-induced GABA release in the CeA (Bajo et al., 2008). Additionally, this enzyme influences the sensitivity of $\mathrm{GABA}_{\mathrm{A}}$ Rs to neurosteroids (Hodge et al., 1999; Fancsik et al., 2000; Brussaard and Koksma, 2003; Harney et al., 2003). Thus, a PKC-induced reduction in the neurosteroid sensitivity of $\mathrm{GABA}_{\mathrm{A}}$ Rs (Brussaard and Koksma, 2003; Harney et al., 2003 but see Fancsik et al., 2000) following ethanol administration has been suggested to contribute to an increase in alcohol consumption as a consequence of the reduced neurosteroid sensitivity (Morrow et al., 2006, also see below). However, the relationship between alcohol intake and neurosteroids is complex, being both context and dose-related. Thus, for example, low doses of $5 \alpha 3 \alpha$-THPROG increased while high doses reduced alcohol intake in C57 mice (Ford et al., 2005). Equally, the progesterone metabolite reduced alcohol intake in alcohol-dependent rodents, while promoting ethanol consumption in non-dependent animals (Morrow et al., 2001). Moreover, tolerance to the ethanol-induced increase in neurosteroid levels developed in alcohol-dependent animals (Khisti et al., 2005) and this adaptation may contribute to the excessive alcohol consumption in such animals (reviewed in Morrow et al., 2006). Conversely, heightened ethanol sensitivity, associated with increased neurosteroid levels has been suggested to prevent excessive alcohol consumption (Morrow et al., 2006). Thus, restoration of ethanol sensitivity may have a therapeutic advantage for the treatment of alcohol dependence, but this remains to be tested in humans.

Interestingly, in addition to $\mathrm{CRH}$, other anxiogenic neuropeptides have been consistently implicated in the development of alcohol dependence (Heilig and Koob, 2007). Thus, the potential of these neuropeptide signaling systems to influence neurosteroidogenesis during the development of alcohol and indeed, other types of drug dependence, deserves further investigation. An improved understanding of how neurosteroids and neuropeptidemediated signaling systems interact at different levels of the neuroaxis may provide insights into the pathology of not only alcohol dependence, but also that of other drugs of abuse.

\section{SUMMARY AND CONCLUSION}

Since the seminal finding that mild stress elevates brain levels of neurosteroids in rodents (Purdy et al., 1991), a growing body of evidence has implicated $\mathrm{GABA}_{\mathrm{A}} \mathrm{R}$-active neurosteroids as important mediators of the complex neuronal adaptations underpinning the response to acute and chronic stress challenges. Moreover, neurosteroids may represent important but overlooked molecular players of the early programming of the stress response.

Converging data from the clinic and from animal models indicates a close association between early life stress experiences and the development of highly debilitating psychiatric conditions including anxiety disorders, depression, and drug addiction. Of relevance to neurosteroids, the impairment of brain signals mediated by $\mathrm{GABA}_{\mathrm{A}}$ Rs is associated with early life adversities. However, the contribution made by these potent, endogenous, $G_{A B A} R$ modulators to the pathophysiology of these psychiatric conditions is only now beginning to emerge. This realization is being complemented by a better understanding of the role neurosteroids play during early neuronal development and of their involvement in the programming of the stress response. Collectively, this research suggests that neurosteroids, or drugs that influence neurosteroid synthesis, may offer a novel therapeutic approach to the treatment of stress-related disturbances.

Many psychiatric disturbances have a recognized mixed genetic and environmental basis such that a genetic predisposition does not always imply an abnormal phenotype in the absence of significant environmental challenges, e.g., early life stress. As an example, polymorphisms of the $G_{A B A} R \alpha 2$ subunit, a protein that is highly expressed in stress-related neuronal circuits, confer susceptibility to cocaine addiction, but only when these genetic abnormalities are coincident with previous traumatic early life stress experiences (Enoch et al., 2010). Although enzyme expression and function is known to be sensitive to epigenetic regulation, the molecular mechanisms governing the neuron-selective expression and function of the neurosteroid enzymatic machinery are still poorly 
understood. Significant advances in this field of research and the development of neurosteroid-based therapeutic strategies will require such mechanisms to be elucidated together with a better understanding of their sensitivity to environmental influences.

\section{REFERENCES}

Agis-Balboa, R. C., Pinna, G., Zhubi, A., Maloku, E., Veldic, M., Costa, E., and Guidotti, A. (2006). Characterization of brain neurons that express enzymes mediating neurosteroid biosynthesis. Proc. Natl. Acad. Sci. U.S.A. 103, 14602-14607.

Akk, G., Li, P., Bracamontes, J., Reichert, D. E., Covey, D. F., and Steinbach, J. H. (2008). Mutations of the GABA-A receptor $\alpha 1$ subunitM1 domain reveal unexpected complexity for modulation by neuroactive steroids. Mol. Pharmacol. 74, 614-627.

Akk, G., Shu, H. J., Wang, C., Steinbach, J. H., Zorumski, C. F., Covey, D. F., and Mennerick, S. (2005). Neurosteroid access to the GABAA receptor. J. Neurosci. 25, 11605-11613.

Alfarez, D. N., Joels, M., and Krugers, H. J. (2003). Chronic unpredictable stress impairs long-term potentiation in rat hippocampal CA1 area and dentate gyrus in vitro. Eur. J. Neurosci. 17, 1928-1934.

Alfarez, D. N., Wiegert, O., Joels, M., and Krugers, H. J. (2002). Corticosterone and stress reduce synaptic potentiation in mouse hippocampal slices with mild stimulation. Neuroscience 115, 1119-1126.

Avishai-Eliner, S., Eghbal-Ahmadi, M., Tabachnik, E., Brunson, K. L., and Baram, T. Z. (2001). Down-regulation of hypothalamic corticotropin-releasing hormone messenger ribonucleic acid (mRNA) precedes early-life experienceinduced changes in hippocampal glucocorticoid receptor mRNA. Endocrinology 142, 89-97.

Baghai, T. C., di Michele, F., Schule, C., Eser, D., Zwanzger, P., Pasini, A., Romeo, E., and Rupprecht, R. (2005). Plasma concentrations of neuroactive steroids before and after electroconvulsive therapy in major depression. Neuropsychopharmacology 30, 1181-1186.

Bajo, M., Cruz, M. T., Siggins, G. R., Messing, R., and Roberto, M. (2008). Protein kinase $\mathrm{C}$ epsilon mediation of CRF- and ethanol-induced GABA release in central amygdala. Proc. Natl. Acad. Sci. U.S.A. 105, 8410-8415.

Bale, T. L., Baram, T. Z., Brown, A. S., Goldstein, J. M., Insel, T. R., McCarthy, M. M., Nemeroff, C. B., Reyes, T. M., Simerly, R. B.,
Susser, E. S., and Nestler, E. J. (2010). Early life programming and neurodevelopmental disorders. Biol. Psychiatry 68, 314-319.

Bale, T. L., and Vale, W. W. (2004). CRF and CRF receptors: role in stress responsivity and other behaviors. Annu. Rev. Pharmacol. Toxicol. 44, 525-557.

Bali, B., and Kovacs, K. J. (2003). GABAergic control of neuropeptide gene expression in parvocellular neurons of the hypothalamic paraventricular nucleus. Eur. J. Neurosci. 18, 1518-1526.

Barbaccia, M. L., Roscetti, G., Trabucchi, M., Mostallino, M. C., Concas, A., Purdy, R. H., and Biggio, G. (1996). Time-dependent changes in rat brain neuroactive steroid concentrations and GABAA receptor function after acute stress. Neuroendocrinology 63, 166-172.

Barbaccia, M. L., Serra, M., Purdy, R. H., and Biggio, G. (2001). Stress and neuroactive steroids. Int. Rev. Neurobiol. 46, 243-272.

Barker, D. J. (2002). Fetal programming of coronary heart disease. Trends Endocrinol. Metab. 13, 364-368.

Barker, J. L., Harrison, N. L., Lange, G. D., and Owen, D. G. (1987). Potentiation of gamma-aminobutyricacid-activated chloride conductance by a steroid anaesthetic in cultured rat spinal neurones. J. Physiol. 386, 485-501.

Batarseh, A., and Papadopoulos, V. (2010). Regulation of translocator protein $18 \mathrm{kDa}$ (TSPO) expression in health and disease states. Mol. Cell. Endocrinol. 327, 1-12.

Belelli, D., Casula, A., Ling, A., and Lambert, J. J. (2002). The influence of subunit composition on the interaction of neurosteroids with GABAA receptors. Neuropharmacology 43, 651-661.

Belelli, D., Harrison, N. L., Maguire, J., Macdonald, R. L., Walker, M. C., and Cope, D. W. (2009). Extrasynaptic GABAA receptors: form, pharmacology, and function. J. Neurosci. 29, 12757-12763.

Belelli, D., and Herd, M. B. (2003). The contraceptive agent Provera enhances GABAA receptormediated inhibitory neurotransmission in the rat hippocampus: evidence for endogenous neurosteroids? J. Neurosci. 23 , 10013-10020.

\section{ACKNOWLEDGMENTS}

Supported by the Wellbeing of Women (Grant number RG1265), Tenovus Scotland, AJ Clark Studentship, and the MRC (Grant 1000008).

Belelli, D., and Lambert, J. J. (2005). Neurosteroids: endogenous regulators of the GABAA receptor. Nat. Rev. Neurosci. 6, 565-575.

Bernardi, F., Lanzone, A., Cento, R. M., Spada, R. S., Pezzani, I., Genazzani, A. D., Luisi, S., Luisi, M., Petraglia, F., and Genazzani, A. R. (2000). Allopregnanolone and dehydroepiandrosterone response to corticotropin-releasing factor in patients suffering from Alzheimer's disease and vascular dementia. Eur. J. Endocrinol. 142, 466-471.

Bianchi, M. T., and Macdonald, R. L. (2003). Neurosteroids shift partial agonist activation of GABAA receptor channels from low- to highefficacy gating patterns. J. Neurosci. 23, 10934-10943.

Biggio, G., Concas, A., Follesa, P., Sanna, E., and Serra, M. (2007). Stress, ethanol, and neuroactive steroids. Pharmacol. Ther. 116, 140-171.

Bitran, D., Shiekh, M., and McLeod, M. (1995). Anxiolytic effect of progesterone is mediated by the neurosteroid allopregnanolone at brain GABAA receptors. J. Neuroendocrinol. 7, 171-177.

Blaesse, P., Airaksinen, M. S., Rivera, C., and Kaila, K. (2009). Cationchloride cotransporters and neuronal function. Neuron 61, 820-838.

Bodnoff, S. R., Humphreys, A. G., Lehman, J. C., Diamond, D. M., Rose, G. M., and Meaney, M. J. (1995). Enduring effects of chronic corticosterone treatment on spatial learning, synaptic plasticity, and hippocampal neuropathology in young and mid-aged rats. J. Neurosci. 15 , 61-69.

Bortolato, M., Devoto, P., Roncada, P., Frau, R., Flore, G., Saba, P., Pistritto, G., Soggiu, A., Pisanu, S., Zappala, A., Ristaldi, M. S., Tattoli, M., Cuomo, V., Marrosu, F., and Barbaccia, M. L. (2011) Isolation rearing-induced reduction of brain $5 \alpha$-reductase expression: relevance to dopaminergic impairments. Neuropharmacology 60, 1301-1308.

Boudaba, C., Szabo, K., and Tasker, J. G. (1996). Physiological mapping of local inhibitory inputs to the hypothalamic paraventricular nucleus. $J$. Neurosci. 16, 7151-7160.

Boyd, K. N., Kumar, S., O’Buckley, T. K., Porcu, P., and Morrow, A. L. (2010). Ethanol induction of steroidogenesis in rat adrenal and brain is dependent upon pituitary ACTH release and de novo adrenal StAR synthesis. J. Neurochem. 112, 784-796.

Brown, N., Kerby, J., Bonnert, T. P., Whiting, P. J., and Wafford, K. A. (2002). Pharmacological characterization of a novel cell line expressing human $\alpha_{4} \beta_{3} \delta$ GABAA receptors. $B r$. J. Pharmacol. 136, 965-974.

Brunton, P. J., McKay, A. J., Ochedalski, T., Piastowska, A., Rebas, E. Lachowicz, A., and Russell, J. A. (2009). Central opioid inhibition of neuroendocrine stress responses in pregnancy in the rat is induced by the neurosteroid allopregnanolone. J. Neurosci. 29, 6449-6460.

Brunton, P. J., and Russell, J. A. (2008). The expectant brain: adapting for motherhood. Nat. Rev. Neurosci. 9, 11-25.

Brunton, P. J., and Russell, J. A. (2010). Prenatal social stress in the rat programmes neuroendocrine and behavioural responses to stress in the adult offspring: sex-specific effects. J. Neuroendocrinol. 22, 258-271.

Brunton, P. J., and Russell, J. A. (2011). Neuroendocrine control of maternal stress responses and fetal programming by stress in pregnancy. Prog. Neuropsychopharmacol. Biol. Psychiatry 35, 1178-1191.

Brussaard, A. B., Kits, K. S., Baker, R. E., Willems, W. P., Leyting-Vermeulen, J. W., Voorn, P., Smit, A. B., Bicknell, R. J., and Herbison, A. E. (1997). Plasticity in fast synaptic inhibition of adult oxytocin neurons caused by switch in GABAA receptor subunit expression. Neuron 19, 1103-1114.

Brussaard, A. B., and Koksma, J. J. (2003). Conditional regulation of neurosteroid sensitivity of GABAA receptors. Ann. N. Y. Acad. Sci. 1007, 29-36.

Caldji, C., Diorio, J., and Meaney, M. J. (2003). Variations in maternal care alter GABAA receptor subunit expression in brain regions associated with fear. Neuropsychopharmacology 28, 1950-1959.

Callachan, H., Cottrell, G. A., Hather, N. Y., Lambert, J. J., Nooney, J. M., and Peters, J. A. (1987). Modulation of the GABAA receptor by progesterone metabolites. Proc. R. Soc. Lond. B Biol. Sci. 231, 359-369. 
Carboni, E., Wieland, S., Lan, N. C., and Gee, K. W. (1996). Anxiolytic properties of endogenously occurring pregnanediols in two rodent models of anxiety. Psychopharmacology (Berl.) 126, 173-178.

Carta, M., Mameli, M., and Valenzuela, C. F. (2004). Alcohol enhances GABAergic transmission to cerebellar granule cells via an increase in golgi cell excitability. J. Neurosci. 24, 3746-3751.

Chisari, M., Eisenman, L. N., Covey, D. F., Mennerick, S., and Zorumski, C. F. (2010). The sticky issue of neurosteroids and GABAA receptors. Trends Neurosci. 33, 299-306.

Cole, R. L., and Sawchenko, P. E. (2002). Neurotransmitter regulation of cellular activation and neuropeptide gene expression in the paraventricular nucleus of the hypothalamus. $J$. Neurosci. 22, 959-969.

Cooper, E. J., Johnston, G. A., and Edwards, F. A. (1999). Effects of a naturally occurring neurosteroid on GABAA IPSCs during development in rat hippocampal or cerebellar slices. J. Physiol. 521(Pt 2), 437-449.

Corpéchot, C., Young, J., Calvel, M., Wehrey, C., Veltz, J. N., Touyer, G., Mouren, M., Prasad, V. V., Banner, C., and Sjovall, J. (1993). Neurosteroids: 3 alpha-hydroxy-5 alphapregnan-20-one and its precursors in the brain, plasma, and steroidogenic glands of male and female rats. Endocrinology 133, 1003-1009.

Crawley, J. N., Glowa, J. R., Majewska, M. D., and Paul, S. M. (1986). Anxiolytic activity of an endogenous adrenal steroid. Brain Res. 398, 382-385.

Crossley, K. J., Walker, D. W., Beart, P. M., and Hirst, J. J. (2000). Characterisation of GABAA receptors in fetal, neonatal and adult ovine brain: region and age related changes and the effects of allopregnanolone. $\mathrm{Neu}$ ropharmacology 39, 1514-1522.

Cullinan, W. E. (2000). GABAA receptor subunit expression within hypophysiotropic CRH neurons: a dual hybridization histochemical study. J. Comp. Neurol. 419, 344-351.

Cullinan, W. E., and Wolfe, T. J. (2000). Chronic stress regulates levels of mRNA transcripts encoding beta subunits of the GABAA receptor in the rat stress axis. Brain Res. 887, 118-124.

Cullinan, W. E., Ziegler, D. R., and Herman, J. P. (2008). Functional role of local GABAergic influences on the HPA axis. Brain Struct. Funct. 213, 63-72.
Cunningham, E. T. Jr., and Sawchenko, P. E. (1988). Anatomical specificity of noradrenergic inputs to the paraventricular and supraoptic nuclei of the rat hypothalamus. J. Comp. Neurol. 274, 60-76.

Curley, J. P., Jensen, C. L., Mashoodh, R., and Champagne, F. A. (2011). Social influences on neurobiology and behavior: epigenetic effects during development. Psychoneuroendocrinology 36, 352-371.

Daftary, S. S., Boudaba, C., and Tasker, J. G. (2000). Noradrenergic regulation of parvocellular neurons in the rat hypothalamic paraventricular nucleus. Neuroscience 96, 743-751.

de Kloet, E. R., Joels, M., and Holsboer, F. (2005). Stress and the brain: from adaptation to disease. Nat. Rev. Neurosci. 6, 463-475.

Di, S., Malcher-Lopes, R., Halmos, K. C., and Tasker, J. G. (2003). Nongenomic glucocorticoid inhibition via endocannabinoid release in the hypothalamus: a fast feedback mechanism. J. Neurosci. 23, 4850-4857.

Di, S., Malcher-Lopes, R., Marcheselli, V. L., Bazan, N. G., and Tasker, J. G. (2005). Rapid glucocorticoidmediated endocannabinoid release and opposing regulation of glutamate and gamma-aminobutyric acid inputs to hypothalamic magnocellular neurons. Endocrinology 146, 4292-4301.

Di, S., Maxson, M. M., Franco, A., and Tasker, J. G. (2009). Glucocorticoids regulate glutamate and GABA synapse-specific retrograde transmission via divergent nongenomic signaling pathways. J. Neurosci. 29, 393-401.

Do Rego, J. L., Seong, J. Y., Burel, D., Leprince, J., Luu-The, V., Tsutsui, K., Tonon, M. C., Pelletier, G., and Vaudry, H. (2009). Neurosteroid biosynthesis: enzymatic pathways and neuroendocrine regulation by neurotransmitters and neuropeptides. Front. Neuroendocrinol. 30, 259-301.

Dzhala, V. I., Talos, D. M., Sdrulla, D. A., Brumback, A. C., Mathews, G. C., Benke, T. A., Delpire, E., Jensen, F. E., and Staley, K. J. (2005). NKCC1 transporter facilitates seizures in the developing brain. Nat. Med. 11, 1205-1213.

Eechaute, W. P., Dhooge, W. S., Gao, C. Q., Calders, P., Rubens, R., Weyne, J., and Kaufman, J. M. (1999). Progesterone-transforming enzyme activity in the hypothalamus of the male rat. J. Steroid Biochem. Mol. Biol. 70, 159-167.
Ehrlich, I., Humeau, Y., Grenier, F., Ciocchi, S., Herry, C., and Luthi, A. (2009). Amygdala inhibitory circuits and the control of fear memory. Neuron 62, 757-771.

Engelmann, M., Landgraf, R., and Wotjak, C. T. (2004). The hypothalamicneurohypophysial system regulates the hypothalamic-pituitary-adrenal axis under stress: an old concept revisited. Front. Neuroendocrinol. 25, 132-149.

Enoch, M. A., Hodgkinson, C. A., Yuan, Q., Shen, P. H., Goldman, D., and Roy, A. (2010). The influence of GABRA2, childhood trauma, and their interaction on alcohol, heroin, and cocaine dependence. Biol. Psychiatry 67, 20-27.

Eser, D., di Michele, F., Zwanzger, P. Pasini, A., Baghai, T. C., Schüle, C., Rupprecht, R., and Romeo, E. (2005). Panic induction with cholecystokinin-tetrapeptide (CCK4) Increases plasma concentrations of the neuroactive steroid $3 \alpha, 5 \alpha$ tetrahydrodeoxycorticosterone $(3 \alpha$, $5 \alpha$-THDOC) in healthy volunteers. Neuropsychopharmacology 30, 192-195.

Eser, D., Romeo, E., Baghai, T. C. di Michele, F., Schule, C., Pasini, A., Zwanzger, P., Padberg, F., and Rupprecht, R. (2006). Neuroactive steroids as modulators of depression and anxiety. Neuroscience 138, 1041-1048.

Fancsik, A., Linn, D. M., and Tasker, J. G. (2000). Neurosteroid modulation of GABA IPSCs is phosphorylation dependent. J. Neurosci. 20, 3067-3075.

Farrant, M., and Nusser, Z. (2005). Variations on an inhibitory theme: phasic and tonic activation of GABAA receptors. Nat. Rev. Neurosci. 6, 215-229.

Fenoglio, K. A., Brunson, K. L., AvishaiEliner, S., Stone, B. A., Kapadia, B. J., and Baram, T. Z. (2005). Enduring, handling-evoked enhancement of hippocampal memory function and glucocorticoid receptor expression involves activation of the corticotropin-releasing factor type 1 receptor. Endocrinology 146, 4090-4096.

Flak, J. N., Ostrander, M. M., Tasker, J. G., and Herman, J. P. (2009). Chronic stress-induced neurotransmitter plasticity in the PVN. J. Comp. Neurol. 517, 156-165.

Ford, M. M., Nickel, J. D., Phillips, T. J., and Finn, D. A. (2005). Neurosteroid modulators of GABAA receptors differentially modulate ethanol intake patterns in male C57BL/6J mice. Alcohol. Clin. Exp. Res. 29, 1630-1640.

Francis, D., Diorio, J., Liu, D., and Meaney, M. J. (1999). Nongenomic transmission across generations of maternal behavior and stress responses in the rat. Science 286, 1155-1158.

Francis, D. D., and Meaney, M. J. (1999). Maternal care and the development of stress responses. Curr. Opin. Neurobiol. 9, 128-134.

Fritschy, J. M., and Brunig, I. (2003). Formation and plasticity of GABAergic synapses: physiological mechanisms and pathophysiological implications. Pharmacol. Ther. 98, 299-323.

Fritschy, J. M., and Mohler, H. (1995). GABAA-receptor heterogeneity in the adult rat brain: differential regional and cellular distribution of seven major subunits. J. Comp. Neurol. 359, 154-194.

Gallagher, J. P., Orozco-Cabal, L. F., Liu, J., and Shinnick-Gallagher, P. (2008). Synaptic physiology of central CRH system. Eur. J. Pharmacol. 583, 215-225.

Gao, C. Q., Dhooge, W. S., Kaufman, J. M., Weyne, J. J., and Eechaute, W. P. (2002). Hypothalamic $5 \alpha$-reductase and $3 \alpha$-oxidoreductase activity in the male rat. J. Steroid Biochem. Mol. Biol. 80, 91-98.

Gasior, M., Carter, R. B., and Witkin, J. M. (1999). Neuroactive steroids: potential therapeutic use in neurological and psychiatric disorders. Trends Pharmacol. Sci. 20, 107-112.

Gee, K. W., Bolger, M. B., Brinton, R. E., Coirini, H., and McEwen, B. S. (1988). Steroid modulation of the chloride ionophore in rat brain: structure-activity requirements, regional dependence and mechanism of action. J. Pharmacol. Exp. Ther. 246, 803-812.

Gee, K. W., Chang, W. C., Brinton, R. E., and McEwen, B. S. (1987). GABAdependent modulation of the $\mathrm{Cl}$ ionophore by steroids in rat brain. Eur. J. Pharmacol. 136, 419-423.

Goldwater, D. S., Pavlides, C., Hunter, R. G., Bloss, E. B., Hof, P. R., McEwen, B. S., and Morrison, J. H. (2009). Structural and functional alterations to rat medial prefrontal cortex following chronic restraint stress and recovery. Neuroscience 164, 798-808.

Griffin, L. D., and Mellon, S. H. (1999). Selective serotonin reuptake inhibitors directly alter activity of neurosteroidogenic enzymes. Proc. Natl. Acad. Sci. U.S.A. 96, 13512-13517. 
Grobin, A. C., Heenan, E. J., Lieberman, J. A., and Morrow, A. L. (2003). Perinatal neurosteroid levels influence GABAergic interneuron localization in adult rat prefrontal cortex. J. Neurosci. 23, 1832-1839.

Guidotti, A., and Costa, E. (1998). Can the antidysphoric and anxiolytic profiles of selective serotonin reuptake inhibitors be related to their ability to increase brain $3 \alpha$, $5 \alpha$-tetrahydroprogesterone (allopregnanolone) availability? Biol. Psychiatry 44, 865-873.

Gunn, B. G., Cooper, M. A., Lambert, J. J., and Belelli, D. B. (2010). Neurosteroids Potently Enhance Synaptic GABAA Receptor-Mediated Inhibition in Medial Parvocellular Neurons of the Paraventricular Nucleus of the Mouse Hypothalamus. Program No. 338.26. 2010. Neuroscience Meeting Planner. San Diego, CA: Society for Neuroscience.

Haage, D., Druzin, M., and Johansson, S. (2002). Allopregnanolone modulates spontaneous GABA release via presynaptic Cl- permeability in rat preoptic nerve terminals. Brain Res. 958, 405-413.

Han, S. K., Chong, W., Li, L. H., Lee, I. S., Murase, K., and Ryu, P. D. (2002). Noradrenaline excites and inhibits GABAergic transmission in parvocellular neurons of rat hypothalamic paraventricular nucleus. $J$. Neurophysiol. 87, 2287-2296.

Harney, S. C., Frenguelli, B. G., and Lambert, J. J. (2003). Phosphorylation influences neurosteroid modulation of synaptic GABAA receptors in rat CAl and dentate gyrus neurones. Neuropharmacology 45, 873-883.

Harrison, N. L., and Simmonds, M. A. (1984). Modulation of the GABA receptor complex by a steroid anaesthetic. Brain Res. 323, 287-292.

Harrison, N. L., Vicini, S., and Barker, J. L. (1987). A steroid anesthetic prolongs inhibitory postsynaptic currents in cultured rat hippocampal neurons. J. Neurosci. 7, 604-609.

Heilig, M., and Koob, G. F. (2007). A key role for corticotropin-releasing factor in alcohol dependence. Trends Neurosci. 30, 399-406.

Herd, M. B., Belelli, D., and Lambert, J. J. (2007). Neurosteroid modulation of synaptic and extrasynaptic GABAA receptors. Pharmacol. Ther. 116, 20-34.

Herman, J. P., and Cullinan, W. E. (1997). Neurocircuitry of stress: central control of the hypothalamopituitary-adrenocortical axis. Trends Neurosci. 20, 78-84.

Herman, J. P., Cullinan, W. E., Ziegler, D. R., and Tasker, J. G. (2002). Role of the paraventricular nucleus microenvironment in stress integration. Eur. J. Neurosci. 16, 381-385.

Herman, J. P., Figueiredo, H., Mueller, N. K., Ulrich-Lai, Y., Ostrander, M. M., Choi, D. C., and Cullinan, W. E. (2003). Central mechanisms of stress integration: hierarchical circuitry controlling hypothalamopituitary-adrenocortical responsiveness. Front. Neuroendocrinol. 24, 151-180.

Hewitt, S. A., Wamsteeker, J. I., Kurz, E. U., and Bains, J. S. (2009). Altered chloride homeostasis removes synaptic inhibitory constraint of the stress axis. Nat. Neurosci. $12,438-443$.

Hirst, J. J., Walker, D. W., Yawno, T., and Palliser, H. K. (2009). Stress in pregnancy: a role for neuroactive steroids in protecting the fetal and neonatal brain. Dev. Neurosci. 31, 363-377.

Hodge, C. W., Mehmert, K. K., Kelley, S. P., McMahon, T., Haywood, A., Olive, M. F., Wang, D., SanchezPerez, A. M., and Messing, R. O. (1999). Supersensitivity to allosteric GABAA receptor modulators and alcohol in mice lacking PKCE. Nat. Neurosci. 2, 997-1002.

Holsboer, F. (2000). The corticosteroid receptor hypothesis of depression. Neuropsychopharmacology 23, 477-501.

Hosie, A. M., Clarke, L., da Silva, H., and Smart, T. G. (2009). Conserved site for neurosteroid modulation of GABAA receptors. Neuropharmacology 56, 149-154.

Hosie, A. M., Wilkins, M. E., da Silva, H. M., and Smart, T. G. (2006). Endogenous neurosteroids regulate GABAA receptors through two discrete transmembrane sites. Nature 444, 486-489.

Imaki, T., Nahan, J. L., Rivier, C., Sawchenko, P. E., and Vale, W. (1991). Differential regulation of corticotropin-releasing factor mRNA in rat brain regions by glucocorticoids and stress. J. Neurosci. 11, 585-599.

Izumi, Y., Murayama, K., Tokuda, K., Krishnan, K., Covey, D. F., and Zorumski, C. F. (2007). GABAergic neurosteroids mediate the effects of ethanol on long-term potentiation in rat hippocampal slices. Eur. J. Neurosci. 26, 1881-1888.

Izumi, Y., Tokuda, K., and Zorumski, C. F. (2008). Long-term potentiation inhibition by low-level $\mathrm{N}$ methyl-D-aspartate receptor activation involves calcineurin, nitric oxide, and p38 mitogen-activated protein kinase. Hippocampus 18, 258-265.

Joels, M., Karst, H., Krugers, H. J., and Lucassen, P. J. (2007). Chronic stress: implications for neuronal morphology, function and neurogenesis. Front. Neuroendocrinol. 28 72-96.

Karavolas, H. J., and Hodges, D. R. (1990). Neuroendocrine metabolism of progesterone and related progestins. Ciba Found. Symp. 153, 22-44.

Karst, H., Berger, S., Erdmann, G. Schutz, G., and Joels, M. (2010). Metaplasticity of amygdalar responses to the stress hormone corticosterone. Proc. Natl. Acad. Sci. U.S.A. 107, 14449-14454.

Karst, H., Berger, S., Turiault, M., Tronche, F., Schutz, G., and Joels, M. (2005). Mineralocorticoid receptors are indispensable for nongenomic modulation of hippocampa glutamate transmission by corticosterone. Proc. Natl. Acad. Sci. U.S.A. 102, 19204-19207.

Kehoe, P., Mallinson, K., McCormick, C. M., and Frye, C. A. (2000). Central allopregnanolone is increased in rat pups in response to repeated, short episodes of neonatal isolation. Brain Res. Dev. Brain Res. 124, 133-136.

Keller, E. A., Zamparini, A., Borodinsky, L. N., Gravielle, M. C., and Fiszman, M. L. (2004). Role of allopregnanolone on cerebellar granule cells neurogenesis. Brain Res. Dev. Brain Res. 153, 13-17.

Khisti, R. T., Boyd, K. N., Kumar, S., and Morrow, A. L. (2005). Systemic ethanol administration elevates deoxycorticosterone levels and chronic ethanol exposure attenuates this response. Brain Res. 1049, 104-111.

Khisti, R. T., VanDoren, M. J., O’Buckley, T., and Morrow, A. L. (2003). Neuroactive steroid $3 \alpha$-hydroxy- $5 \alpha$ pregnan-20-one modulates ethanolinduced loss of righting reflex in rats. Brain Res. 980, 255-265.

Kittler, J. T., and Moss, S. J. (2003). Modulation of GABAA receptor activity by phosphorylation and receptor trafficking: implications for the efficacy of synaptic inhibition. Curr. Opin. Neurobiol. 13, 341-347.

Koksma, J. J., Van Kesteren, R. E., Rosahl, T. W., Zwart, R., Smit, A. B., Luddens, H., and Brussaard, A. B. (2003). Oxytocin regulates neurosteroid modulation of GABAA receptors in supraoptic nucleus around parturition. J. Neurosci. 23, 788-797.

Koob, G., and Kreek, M. J. (2007). Stress, dysregulation of drug reward pathways, and the transition to drug dependence. Am. J. Psychiatry 164, 1149-1159.

Koob, G. F. (2008). A role for brain stress systems in addiction. Neuron 59, 11-34.

Koob, G. F., and Le Moal, M. (2001). Drug addiction, dysregulation of reward, and allostasis. Neuropsychopharmacology 24, 97-129.

Koob, G. F., and Zorrilla, E. P. (2010). Neurobiological mechanisms of addiction: focus on corticotropinreleasing factor. Curr. Opin. Investig. Drugs 11, 63-71.

Korosi, A., Shanabrough, M., McClelland, S., Liu, Z. W., Borok, E., Gao, X. B., Horvath, T. L., and Baram, T. Z. (2010). Early-life experience reduces excitation to stressresponsive hypothalamic neurons and reprograms the expression of corticotropin-releasing hormone. $J$. Neurosci. 30, 703-713.

Kullmann, D. M., Ruiz, A., Rusakov, D. M., Scott, R., Semyanov, A., and Walker, M. C. (2005). Presynaptic, extrasynaptic and axonal GABAA receptors in the CNS: where and why? Prog. Biophys. Mol. Biol. 87, 33-46.

Lambert, J. J., Belelli, D., Hill-Venning, C., and Peters, J. A. (1995). Neurosteroids and GABAA receptor function. Trends Pharmacol. Sci. 16, 295-303.

Lambert, J. J., Cooper, M. A., Simmons, R. D., Weir, C. J., and Belelli, D. (2009). Neurosteroids: endogenous allosteric modulators of GABAA receptors. Psychoneuroendocrinology 34(Suppl. 1), S48-S58.

Lambert, J. J., Peters, J. A., and Cottrell, G. A. (1987). Actions of synthetic and endogenous steroids on the GABAA receptor. Trends Pharmacol. Sci. 8, 224-227.

Levitt, N. S., Lambert, E. V., Woods, D., Hales, C. N., Andrew, R., and Seckl, J. R. (2000). Impaired glucose tolerance and elevated blood pressure in low birth weight, non obese, young south african adults: early programming of cortisol axis. J. Clin. Endocrinol. Metab. 85, 4611-4618.

Li, X., Bertics, P. J., and Karavolas, H. J. (1997). Regional distribution of cytosolic and particulate $5 \alpha$-dihydroprogesterone $3 \alpha$ hydroxysteroid oxidoreductases in female rat brain. J. Steroid Biochem. Mol. Biol. 60, 311-318.

Liston, C., Miller, M. M., Goldwater, D. S., Radley, J. J., Rocher, A. B., Hof, P. R., Morrison, J. H., and McEwen, B. S. (2006). Stress-induced alterations in prefrontal cortical dendritic morphology predict selective impairments in perceptual attentional set-shifting. J. Neurosci. 26, 7870-7874.

Longone, P., Rupprecht, R., Manieri, G. A., Bernardi, G., Romeo, E., and Pasini, A. (2008). The complex roles of neurosteroids in depression and anxiety disorders. Neurochem. Int. 52, 596-601. 
Luchetti, S., Huitinga, I., and Swaab, D. F. (2011). Neurosteroid and GABAA receptor alterations in Alzheimer's disease, Parkinson's disease and multiple sclerosis. Neuroscience 191, 6-21.

Ludwig, M., and Leng, G. (2006). Dendritic peptide release and peptidedependent behaviours. Nat. Rev. Neurosci. 7, 126-136.

Lupien, S. J., McEwen, B. S., Gunnar, M. R., and Heim, C. (2009). Effects of stress throughout the lifespan on the brain, behaviour and cognition. Nat. Rev. Neurosci. 10, 434-445.

Magarinos, A. M., and McEwen, B. S. (1995). Stress-induced atrophy of apical dendrites of hippocampal $\mathrm{CA} 3 \mathrm{c}$ neurons: involvement of glucocorticoid secretion and excitatory amino acid receptors. Neuroscience 69, 89-98.

Maguire, J., and Mody, I. (2007). Neurosteroid synthesis-mediated regulation of GABAA receptors: relevance to the ovarian cycle and stress. $J$. Neurosci. 27, 2155-2162.

Maguire, J., and Mody, I. (2008). GABAAR plasticity during pregnancy: relevance to postpartum depression. Neuron 59, 207-213.

Maguire, J., and Mody, I. (2009). Steroid hormone fluctuations and GABAAR plasticity. Psychoneuroendocrinology 34(Suppl. 1), S84-S90.

Makino, S., Gold, P. W., and Schulkin, J. (1994). Corticosterone effects on corticotropin-releasing hormone mRNA in the central nucleus of the amygdala and the parvocellular region of the paraventricular nucleus of the hypothalamus. Brain Res. 640, 105-112.

Matsumoto, K., Uzunova, V., Pinna, G., Taki, K., Uzunov, D. P., Watanabe, H., Mienville, J. M., Guidotti, A., and Costa, E. (1999). Permissive role of brain allopregnanolone content in the regulation of pentobarbital-induced righting reflex loss. Neuropharmacology 38, 955-963.

McEwen, B. S. (2003). Early life influences on life-long patterns of behaviour and health. Ment. Retard Dev. Disabil. Res. Rev. 9, 149-154.

McEwen, B. S. (2010). Stress, sex, and neural adaptation to a changing environment: mechanisms of neuronal remodeling. Ann. N. Y. Acad. Sci. 1204(Suppl.), E38-E59.

McGowan, P. O., Sasaki, A., D'Alessio, A. C., Dymov, S., Labonte, B., Szyf, M., Turecki, G., and Meaney, M. J. (2009). Epigenetic regulation of the glucocorticoid receptor in human brain associates with childhood abuse. Nat. Neurosci. 12, 342-348.
Meaney, M. J., Viau, V., Bhatnagar, S., Betito, K., Iny, L. J., O’Donnell, D., and Mitchell, J. B. (1991). Cellular mechanisms underlying the development and expression of individual differences in the hypothalamicpituitary-adrenal stress response. $J$. Steroid Biochem. Mol. Biol. 39, 265-274.

Melcangi, R. C., Celotti, F., Castano, P., and Martini, L. (1993). Differential localisation of the $5 \alpha$-reductase and the $3 \alpha$-hydroxysteroid dehydrogenase in neuronal and glial cell cultures. Endocrinology 132, 1252-1259.

Mellon, S. H. (2004). "Synthesis, enzymes localizations and regulation of neurosteroids," in Neurosteroid Effects in the Central Nervous System: The Role of the GABAAR. Methods and New Frontiers in Neuroscience, ed. S. S. Smith (Boca Raton: CRC Press), 1-46.

Mellon, S. H., and Griffin, L. D. (2002). Neurosteroids: biochemistry and clinical significance. Trends Endocrinol. Metab. 13, 35-43.

Mellon, S. H., and Vaudry, H. (2001). Biosynthesis of neurosteroids and regulation of their synthesis. Int. Rev. Neurobiol. 46, 33-78.

Mennerick, S., He, Y., Jiang, X., Manion, B. D., Wang, M., Shute, A., Benz, A., Evers, A. S., Covey, D. F., and Zorumski, C. F. (2004). Selective antagonism of $5 \alpha$-reduced neurosteroid effects at GABAA receptors. Mol. Pharmacol. 65, 1191-1197.

Mihalek, R. M., Banerjee, P. K., Korpi, E. R., Quinlan, J. J., Firestone, L. L., Mi, Z. P., Lagenaur, C., Tretter, V., Sieghart, W., Anagnostaras, S. G., Sage, J. R., Fanselow, M. S., Guidotti, A., Spigelman, I., Li, Z., DeLorey, T. M., Olsen, R. W., and Homanics, G. E. (1999). Attenuated sensitivity to neuroactive steroids in $\gamma$ aminobutyrate type A receptor delta subunit knockout mice. Proc. Natl. Acad. Sci. U.S.A. 96, 12905-12910.

Miklos, I. H., and Kovacs, K. J. (2002). GABAergic innervation of corticotropin-releasing hormone (CRH)-secreting parvocellular neurons and its plasticity as demonstrated by quantitative immunoelectron microscopy. Neuroscience 113, 581-592.

Mitev, Y. A., Darwish, M., Wolf, S. S., Holsboer, F., Almeida, O. F., and Patchev, V. K. (2003). Gender differences in the regulation of $3 \alpha$-hydroxysteroid dehydrogenase in rat brain and sensitivity to neurosteroid-mediated stress protection. Neuroscience 120, 541-549.

Mitra, R., and Sapolsky, R. M. (2008). Acute corticosterone treatment is sufficient to induce anxiety and amygdaloid dendritic hypertrophy. Proc. Natl. Acad. Sci. U.S.A. 105, 5573-5578.

Molina-Hernandez, M., TellezAlcantara, N. P., Garcia, J. P., Lopez, J. I., and Jaramillo, M. T. (2005). Antidepressant-like actions of intra-accumbens infusions of allopregnanolone in ovariectomized Wistar rats. Pharmacol. Biochem. Behav. 80, 401-409.

Morrow, A. L., Porcu, P., Boyd, K. N., and Grant, K. A. (2006). Hypothalamicpituitary-adrenal axis modulation of GABAergic neuroactive steroids influences ethanol sensitivity and drinking behavior. Dialogues Clin. Neurosci. 8, 463-477.

Morrow, A. L., VanDoren, M. J., Penland, S. N., and Matthews, D. B. (2001). The role of GABAergic neuroactive steroids in ethanol action, tolerance and dependence. Brain Res. Brain Res. Rev. 37, 98-109.

Motzo, C., Porceddu, M. L., Maira, G., Flore, G., Concas, A., Dazzi, L., and Biggio, G. (1996). Inhibition of basal and stress-induced dopamine release in the cerebral cortex and nucleus accumbens of freely moving rats by the neurosteroid allopregnanolone. J. Psychopharmacol. $10,266-272$.

Murgatroyd, C., Patchev, A. V., Wu, Y., Micale, V., Bockmuhl, Y., Fischer, D., Holsboer, F., Wotjak, C T., Almeida, O. F., and Spengler, D. (2009). Dynamic DNA methylation programs persistent adverse effects of early-life stress. Nat. Neurosci. 12, 1559-1566.

Neigh, G. N., Gillespie, C. F., and Nemeroff, C. B. (2009). The neurobiological toll of child abuse and neglect. Trauma Violence Abuse 10 389-410.

Nguyen, P. N., Billiards, S. S., Walker, D. W., and Hirst, J. J. (2003). Changes in $5 \alpha$-pregnane steroids and neurosteroidogenic enzyme expression in fetal sheep with umbilicoplacental embolization. Pediatr. Res. 54 840-847.

Nguyen, P. N., Yan, E. B., CastilloMelendez, M., Walker, D. W., and Hirst, J. J. (2004). Increased allopregnanolone levels in the fetal sheep brain following umbilical cord occlusion. J. Physiol. (Lond.) 560, 593-602.

Nie, Z., Schweitzer, P., Roberts, A. J., Madamba, S. G., Moore, S. D. and Siggins, G. R. (2004). Ethanol augments GABAergic transmission in the central amygdala via CRF1 receptors. Science 303, 1512-1514.

Nusser, Z., Sieghart, W., and Somogyi, P. (1998). Segregation of different
GABAA receptors to synaptic and extrasynaptic membranes of cerebellar granule cells. J. Neurosci. 18, 1693-1703.

Olsen, R. W., and Sieghart, W. (2008). International Union of Pharmacology. LXX. Subtypes of $\gamma$ aminobutyric acidA receptors: classification on the basis of subunit composition, pharmacology, and function. Update. Pharmacol. Rev. 60, 243-260.

Olsen, R. W., and Sieghart, W. (2009). GABAA receptors: subtypes provide diversity of function and pharmacology. Neuropharmacology 56, 141-148.

Orchinik, M., Weiland, N. G., and McEwen, B. S. (1995). Chronic exposure to stress levels of corticosterone alters GABAA receptor subunit mRNA levels in rat hippocampus. Brain Res. Mol. Brain Res. 34, 29-37.

Owens, M. J., and Nemeroff, C. B. (1991). Physiology and pharmacology of corticotropin-releasing factor. Pharmacol. Rev. 43, 425-473.

Padberg, F., di Michele, F., Zwanzger, P., Romeo, E., Bernardi, G., Schule, C., Baghai, T. C., Ella, R., Pasini, A., and Rupprecht, R. (2002). Plasma concentrations of neuroactive steroids before and after repetitive transcranial magnetic stimulation (rTMS) in major depression. Neuropsychopharmacology 27, 874-878.

Papadopoulos, V., Baraldi, M., Guilarte, T. R., Knudsen, T. B., Lacapere, J. J., Lindemann, P., Norenberg, M. D., Nutt, D., Weizman, A., Zhang, M. R., and Gavish, M. (2006). Translocator protein $(18 \mathrm{kDa})$ : new nomenclature for the peripheraltype benzodiazepine receptor based on its structure and molecular function. Trends Pharmacol. Sci. 27, 402-409.

Patchev, V. K., Hassan, A. H., Holsboer, D. F., and Almeida, O. F. (1996). The neurosteroid tetrahydroprogesterone attenuates the endocrine response to stress and exerts glucocorticoid-like effects on vasopressin gene transcription in the rat hypothalamus. Neuropsychopharmacology 15 , 533-540.

Patchev, V. K., Montkowski, A., Rouskova, D., Koranyi, L., Holsboer, F., and Almeida, O. F. (1997). Neonatal treatment of rats with the neuroactive steroid tetrahydrodeoxycorticosterone (THDOC) abolishes the behavioral and neuroendocrine consequences of adverse early life events. J. Clin. Invest. 99, 962-966. 
Patchev, V. K., Shoaib, M., Holsboer, F., and Almeida, O. F. (1994). The neurosteroid tetrahydroprogesterone counteracts corticotropinreleasing hormone-induced anxiety and alters the release and gene expression of corticotropinreleasing hormone in the rat hypothalamus. Neuroscience 62, 265-271.

Paul, S. M., and Purdy, R. H. (1992). Neuroactive steroids. FASEB J. 6, 2311-2322.

Peters, J. A., Kirkness, E. F., Callachan, H., Lambert, J. J., and Turner, A. J. (1988). Modulation of the GABAA receptor by depressant barbiturates and pregnane steroids. Br. J. Pharmacol. 94, 1257-1269.

Pinna, G. (2010). In a mouse model relevant for post-traumatic stress disorder, selective brain steroidogenic stimulants (SBSS) improve behavioral deficits by normalizing allopregnanolone biosynthesis. Behav. Pharmacol. 21, 438-450.

Pinna, G., Costa, E., and Guidotti, A. (2004). Fluoxetine and norfluoxetine stereospecifically facilitate pentobarbital sedation by increasing neurosteroids. Proc. Natl. Acad. Sci. U.S.A. 101, 6222-6225.

Pinna, G., Costa, E., and Guidotti, A. (2009). SSRIs act as selective brain steroidogenic stimulants (SBSSs) at low doses that are inactive on 5-HT reuptake. Curr. Opin. Pharmacol. 9, 24-30.

Plotsky, P. M., and Meaney, M. J. (1993). Early, postnatal experience alters hypothalamic corticotropinreleasing factor (CRF) mRNA, median eminence CRF content and stress-induced release in adult rats. Brain Res. Mol. Brain Res. 18, 195-200.

Puia, G., Mienville, J. M., Matsumoto, K., Takahata, H., Watanabe, H., Costa, E., and Guidotti, A. (2003). On the putative physiological role of allopregnanolone on GABAA receptor function. Neuropharmacolog $y 44$, 49-55.

Purdy, R. H., Morrow, A. L., Moore, P. H. Jr., and Paul, S. M. (1991). Stress-induced elevations of $\gamma$ aminobutyric acid type A receptoractive steroids in the rat brain. Proc. Natl. Acad. Sci. U.S.A. 88, 4553-4557.

Radley, J. J., Rocher, A. B., Janssen, W. G., Hof, P. R., McEwen, B. S., and Morrison, J. H. (2005). Reversibility of apical dendritic retraction in the rat medial prefrontal cortex following repeated stress. Exp. Neurol. 196, 199-203.
Radley, J. J., Rocher, A. B., Rodriguez, A., Ehlenberger, D. B., Dammann, M., McEwen, B. S., Morrison, J. H., Wearne, S. L., and Hof, P. R. (2008). Repeated stress alters dendritic spine morphology in the rat medial prefrontal cortex. J. Comp. Neurol. 507, 1141-1150.

Rasmussen, D. D., Boldt, B. M., Bryant, C. A., Mitton, D. R., Larsen, S. A., and Wilkinson, C. W. (2000). Chronic daily ethanol and withdrawal: 1. Long-term changes in the hypothalamo-pituitary-adrenal axis. Alcohol. Clin. Exp. Res. 24, 1836-1849.

Reddy, D. S. (2006). Physiological role of adrenal deoxycorticosteronederived neuroactive steroids in stress-sensitive conditions. Neuroscience 138, 911-920.

Reddy, D. S., and Jian, K. (2010). The testosterone-derived neurosteroid androstanediol is a positive allosteric modulator of GABAA receptors. J. Pharmacol. Exp. Ther. 334, 1031-1041.

Reddy, D. S., and Rogawski, M. A. (2002). Stress-induced deoxycorticosterone-derived neurosteroids modulate GABAA receptor function and seizure susceptibility. J. Neurosci. 22, 3795-3805.

Repetti, R. L., Taylor, S. E., and Seeman, T. E. (2002). Risky families: family social environments and the mental and physical health of offspring. Psychol. Bull. 128, 330-366.

Represa, A., and Ben-Ari, Y. (2005). Trophic actions of GABA on neuronal development. Trends Neurosci. $28,278-283$.

Rissman, R. A., De Blas, A. L., and Armstrong, D. M. (2007). GABAA receptors in aging and Alzheimer's disease. J. Neurochem. 103, 1285-1292.

Roberto, M., Madamba, S. G., Moore, S. D., Tallent, M. K., and Siggins, G. R. (2003). Ethanol increases GABAergic transmission at both pre- and postsynaptic sites in rat central amygdala neurons. Proc. Natl. Acad. Sci. U.S.A. 100, 2053-2058.

Romeo, E., Strohle, A., Spalletta, G., di Michele, F., Hermann, B., Holsboer, F., Pasini, A., and Rupprecht, R. (1998). Effects of antidepressant treatment on neuroactive steroids in major depression. Am. J. Psychiatry 155, 910-913.

Roozendaal, B., McEwen, B. S., and Chattarji, S. (2009). Stress, memory and the amygdala. Nat. Rev. Neurosci. 10, 423-433.
Rouge-Pont, F., Mayo, W., Marinelli, M., Gingras, M., Le Moal, M., and Piazza, P. V. (2002). The neurosteroid allopregnanolone increases dopamine release and dopaminergic response to morphine in the rat nucleus accumbens. Eur. J. Neurosci. $16,169-173$.

Ruiz, A., Campanac, E., Scott, R. S., Rusakov, D. A., and Kullmann, D. M. (2010). Presynaptic GABAA receptors enhance transmission and LTP induction at hippocampal mossy fiber synapses. Nat. Neurosci. 13 431-438.

Rupprecht, R. (2003). Neuroactive steroids: mechanisms of action and neuropsychopharmacological properties. Psychoneuroendocrinology 28 139-168.

Rupprecht, R., Papadopoulos, V., Rammes, G., Baghai, T. C., Fan, J., Akula, N., Groyer, G., Adams, D., and Schumacher, M. (2010) Translocator protein $(18 \mathrm{kDa})$ (TSPO) as a therapeutic target for neurological and psychiatric disorders. Nat. Rev. Drug Discov. 9 , 971-988.

Rupprecht, R., Rammes, G., Eser, D., Baghai, T. C., Schule, C., Nothdurfter, C., Troxler, T., Gentsch, C., Kalkman, H. O., Chaperon, F., Uzunov, V., McAllister, K. H., Bertaina-Anglade, V., La Rochelle, C. D., Tuerck, D., Floesser, A., Kiese, B., Schumacher, M., Landgraf, R., Holsboer, F., and Kucher, K. (2009). Translocator protein (18 $\mathrm{kD})$ as target for anxiolytics without benzodiazepine-like side effects. Science 325, 490-493.

Saalmann, Y. B., Kirkcaldie, M. T., Waldron, S., and Calford, M. B. (2007). Cellular distribution of the GABAA receptor-modulating $3 \alpha$-hydroxy, $5 \alpha$-reduced pregnane steroids in the adult rat brain. $J$. Neuroendocrinol. 19, 272-284.

Sanchez, M. M., Ladd, C. O., and Plotsky, P. M. (2001). Early adverse experience as a developmental risk factor for later psychopathology: evidence from rodent and primate models. Dev. Psychopathol. 13 , 419-449.

Sánchez, P., Torres, J. M., Gavete, P., and Ortega, E. (2008). Effects of swim stress on mRNA and protein levels of steroid $5 \alpha$-reductase isozymes in adult rat brain. Neurochem. Int. 52, 426-431.

Sanna, E., Cuccheddu, T., Serra, M., Concas, A., and Biggio, G. (1992). Carbon dioxide inhalation reduces the function of GABAA receptors in the rat brain. Eur. J. Pharmacol. 216, 457-458.

Sanna, E., Talani, G., Busonero, F., Pisu, M. G., Purdy, R. H., Serra, M., and Biggio, G. (2004). Brain steroidogenesis mediates ethanol modulation of GABAA receptor activity in rat hippocampus. J. Neurosci. 24 , 6521-6530.

Sapolsky, R. M., and Meaney, M. J. (1986). Maturation of the adrenocortical stress response: neuroendocrine control mechanisms and the stress hyporesponsive period. Brain Res. 396, 64-76.

Schlaepfer, T. E., Cohen, M. X., Frick, C., Kosel, M., Brodesser, D., Axmacher, N., Joe, A. Y., Kreft, M., Lenartz, D. and Sturm, V. (2008). Deep brain stimulation to reward circuitry alleviates anhedonia in refractory major depression. Neuropsychopharmacology 33, 368-377.

Schule, C., Baghai, T. C., Eser, D., and Rupprecht, R. (2009). Hypothalamic-pituitaryadrenocortical system dysregulation and new treatment strategies in depression. Expert Rev. Neurother. 9, 1005-1019.

Schule, C., di Michele, F., Baghai, T. Romeo, E., Bernardi, G., Zwanzger, P., Padberg, F., Pasini, A., and Rupprecht, R. (2003). Influence of sleep deprivation on neuroactive steroids in major depression. $\mathrm{Neu}$ ropsychopharmacology 28, 577-581.

Schule, C., Romeo, E., Uzunov, D. P., Eser, D., di Michele, F., Baghai, T. C., Pasini, A., Schwarz, M. Kempter, H., and Rupprecht, R. (2006). Influence of mirtazapine on plasma concentrations of neuroactive steroids in major depression and on 3alpha-hydroxysteroid dehydrogenase activity. Mol. Psychiatry 11, 261-272.

Selye, H. (1941). Anaesthetic effects of steroid hormones. Proc. Soc. Exp. Biol. Med. 46, 116-121.

Semba, J., Wakuta, M., Maeda, J., and Suhara, T. (2004). Nicotine withdrawal induces subsensitivity of hypothalamic-pituitary-adrenal axis to stress in rats: implications for precipitation of depression during smoking cessation. Psychoneuroendocrinology 29, 215-226.

Serra, M., Pisu, M. G., Littera, M., Papi, G., Sanna, E., Tuveri, F., Usala, L., Purdy, R. H., and Biggio, G. (2000). Social isolation-induced decreases in both the abundance of neuroactive steroids and GABAA receptor function in rat brain. J. Neurochem. 75 , 732-740. 
Serra, M., Pisu, M. G., Mostallino, M. C., Sanna, E., and Biggio, G. (2008). Changes in neuroactive steroid content during social isolation stress modulate GABAA receptor plasticity and function. Brain Res. Rev. 57, 520-530.

Serra, M., Pisu, M. G., Muggironi, M., Parodo, V., Papi, G., Sari, R., Dazzi, L., Spiga, F., Purdy, R. H., and Biggio, G. (2001). Opposite effects of short- versus long-term administration of fluoxetine on the concentrations of neuroactive steroids in rat plasma and brain. Psychopharmacology (Berl.) 158, 48-54.

Shen, H., Sabaliauskas, N., Sherpa, A., Fenton, A. A., Stelzer, A., Aoki, C., and Smith, S. S. (2010). A critical role for $\alpha 4 \beta \delta$ GABAA receptors in shaping learning defeci8ts at puberty in mice. Science 327, 1515-1518.

Sierra, A. (2004). Neurosteroids: the StAR protein in the brain. J. Neuroendocrinol. 16, 787-793.

Singh, C., Liu, L., Wang, J. M., Irwin, R. W., Yao, J., Chen, S., Henry, S., Thompson, R. F., and Brinton, R. D. (2011). Allopregnanolone restores hippocampal-dependent learning and memory and neural progenitor survival in aging $3 \times \mathrm{TgAD}$ and nonTg mice. Neurobiol. Aging. doi: 10.1016/j.neurobiolaging.2011.06. 008

Smith, S. S., Ruderman, Y., Frye, C., Homanics, G., and Yuan, M. (2006). Steroid withdrawal in the mouse results in anxiogenic effects of $3 \alpha, 5 \beta$-THP: a possible model of premenstrual dysphoric disorder. Psychopharmacology (Berl.) 186, 323-333.

Sotiropoulos, I., Catania, C., Pinto, L. G., Silva, R., Pollerberg, G. E., Takashima, A., Sousa, N., and Almeida, O. F. (2011). Stress acts cumulatively to precipitate Alzheimer's disease-like tau pathology and cognitive deficits. $J$. Neurosci. 31, 7840-7847.

Sundstrom-Poromaa, I. (2004). "Premenstrual dysphoric disorder," in Neurosteroid Effects in the Central Nervous System, ed. S. S. Smith (Boca Raton: CRC Press), 291-304.

Swanson, L. W., Sawchenko, P. E., Rivier, J., and Vale, W. W. (1983). Organization of ovine corticotropinreleasing factor immunoreactive cells and fibers in the rat brain: an immunohistochemical study. Neuroendocrinology 36, 165-186.

Swanson, L. W., and Simmons, D. M. (1989). Differential steroid hormone and neural influences on peptide mRNA levels in CRH cells of the paraventricular nucleus: a hybridization histochemical study in the rat. $J$. Comp. Neurol. 285, 413-435.

Szabadics, J., Varga, C., Molnar, G., Olah, S., Barzo, P., and Tamas, G. (2006). Excitatory effect of GABAergic axoaxonic cells in cortical microcircuits. Science 311, 233-235.

Tasker, J. G., and Herman, J. P. (2011). Mechanisms of rapid glucocorticoid feedback inhibition of the hypothalamic-pituitary-adrenal axis. Stress 14, 398-406.

Tokuda, K., Izumi, Y., and Zorumski, C. F. (2011). Ethanol enhances neurosteroidogenesis in hippocampal pyramidal neurons by paradoxical NMDA receptor activation. J. Neurosci. 31, 9905-9909.

Tokuda, K., O’Dell, K. A., Izumi, Y., and Zorumski, C. F. (2010). Midazolam inhibits hippocampal long-term potentiation and learning through dual central and peripheral benzodiazepine receptor activation and neurosteroidogenesis. J. Neurosci. 30, 16788-16795.

Torres, J. M., Ruiz, E., and Ortega, E. (2001). Effects of CRH and ACTH administration on plasma and brain neurosteroid levels. Neurochem. Res. 26, 555-558.

Trauger, J. W., Jiang, A., Stearns, B. A., and LoGrasso, P. V. (2002). Kinetics of allopregnanolone formation catalyzed by human $3 \alpha$-hydroxysteroid dehydrogenase type III (AKR1C2). Biochemistry 41, 13451-13459.

Trigo, F. F., Marty, A., and Stell, B. M. (2008). Axonal GABAA receptors. Eur. J. Neurosci. 28, 841-848.

Tsankova, N., Renthal, W., Kumar, A., and Nestler, E. J. (2007). Epigenetic regulation in psychiatric disorders. Nat. Rev. Neurosci. 8, 355-367.

Tsutsui, K. (2008). Neurosteroids in the Purkinje cell: biosynthesis, mode of action and functional significance. Mol. Neurobiol. 37, 116-125.

Uchida, S., Noda, E., Kakazu, Y., Mizoguchi, Y., Akaike, N., and Nabekura, J. (2002). Allopregnanolone enhancement of GABAergic transmission in rat medial preoptic area neurons. Am. J. Physiol. Endocrinol. Metab. 283, E1257-E1265.

Ulrich-Lai, Y. M., and Herman, J. P. (2009). Neural regulation of endocrine and autonomic stress responses. Nat. Rev. Neurosci. 10, 397-409.

Uzunov, D. P., Cooper, T. B., Costa, E., and Guidotti, A. (1996). Fluoxetine-elicited changes in brain neurosteroid content measured by negative ion mass fragmentography.
Proc. Natl. Acad. Sci. U.S.A. 93, 12599-12604.

Uzunova, V., Sampson, L., and Uzunov, D. P. (2006). Relevance of endogenous 3alpha-reduced neurosteroids to depression and antidepressant action. Psychopharmacology (Berl.) 186, 351-361

Uzunova, V., Sheline, Y., Davis, J. M. Rasmusson, A., Uzunov, D. P., Costa, E., and Guidotti, A. (1998). Increase in the cerebrospinal fluid content of neurosteroids in patients with unipolar major depression who are receiving fluoxetine or fluvoxamine. Proc. Natl. Acad. Sci. U.S.A. 95, 3239-3244.

Vale, W., Spiess, J., Rivier, C., and Rivier, J. (1981). Characterization of a 41-residue ovine hypothalamic peptide that stimulates secretion of corticotropin and beta-endorphin. Science 213, 1394-1397.

VanDoren, M. J., Matthews, D. B., Janis, G. C., Grobin, A. C., Devaud, L. L., and Morrow, A. L. (2000). Neuroactive steroid $3 \alpha$-hydroxy$5 \alpha$-pregnan-20-one modulates electrophysiological and behavioral actions of ethanol. J. Neurosci. 20, 1982-1989.

Verkuyl, J. M., Hemby, S. E., and Joels, M. (2004). Chronic stress attenuates GABAergic inhibition and alters gene expression of parvocellular neurons in rat hypothalamus. Eur. J. Neurosci. 20, 1665-1673.

Verleye, M., Akwa, Y., Liere, P., Ladurelle, N., Pianos, A., Eychenne, B., Schumacher, M., and Gillardin, J. M. (2005). The anxiolytic etifoxine activates the peripheral benzodiazepine receptor and increases the neurosteroid levels in rat brain. Pharmacol. Biochem. Behav. 82, 712-720.

Wang, J. M., Johnston, P. B., Ball, B. G., and Brinton, R. D. (2005). The neurosteroid allopregnanolone promotes proliferation of rodent and human neural progenitor cells and regulates cell-cycle gene and protein expression. J. Neurosci. 25, 4706-4718.

Wang, J. M., Liu, L., Irwin, R. W., Chen, S., and Brinton, R. D. (2008). Regenerative potential of allopregnanolone. Brain Res. Rev. 57, 398-409.

Wang, J. M., Singh, C., Liu, L., Irwin, R. W., Chen, S., Chung, E. J., Thompson, R. F., and Brinton, R. D. (2010). Allopregnanolone reverses neurogenic and cognitive deficits in mouse model of Alzheimer's disease. Proc. Natl. Acad. Sci. U.S.A. 107, 6498-6503.
Weaver, I. C., Cervoni, N., Champagne, F. A., D'Alessio, A. C., Sharma, S., Seckl, J. R., Dymov, S., Szyf, M., and Meaney, M. J. (2004). Epigenetic programming by maternal behavior. Nat. Neurosci. 7, 847-854.

Wei, W., Zhang, N., Peng, Z., Houser, C. R., and Mody, I. (2003). Perisynaptic localization of delta subunitcontaining GABAA receptors and their activation by GABA spillover in the mouse dentate gyrus. J. Neurosci. 23, 10650-10661.

Weill-Engerer, S., David, J. P., Sazdovitch, V., Liere, P., Eychenne, B., Pianos, A., Schumacher, M., Delacourte, A., Baulieu, E. E., and Akwa, Y. (2002). Neurosteroid quantification in human brain regions: comparison between Alzheimer's and nondemented patients. J. Clin Endocrinol. Metab. 87, 5138-5143.

Welberg, L. A., and Seckl, J. R. (2001). Prenatal stress, glucocorticoids and the programming of the brain. J. Neuroendocrinol. 13, 113-128.

Wisden, W., Laurie, D. J., Monyer, H., and Seeburg, P. H. (1992). The distribution of 13 GABAA receptor subunit mRNAs in the rat brain. I. Telencephalon, diencephalon, mesencephalon. J. Neurosci. 12, 1040-1062.

Womack, M. D., Pyner, S., and Barrett-Jolley, R. (2006). Inhibition by $\alpha$-tetrahydrodeoxycorticosterone (THDOC) of pre-sympathetic parvocellular neurones in the paraventricular nucleus of rat hypothalamus. Br. J. Pharmacol. 149, 600-607.

Woolley, C. S., Gould, E., and McEwen, B. S. (1990). Exposure to excess glucocorticoids alters dendritic morphology of adult hippocampal pyramidal neurons. Brain Res. 531, 225-231.

Zimmerberg, B., and Blaskey, L. G. (1998). Prenatal stress effects are partially ameliorated by prenatal administration of the neurosteroid allopregnanolone. Pharmacol. Biochem. Behav. 59, 819-827.

Zimmerberg, B., Brunelli, S. A., and Hofer, M. A. (1994). Reduction of rat pup ultrasonic vocalizations by the neuroactive steroid allopregnanolone. Pharmacol. Biochem. Behav. 47, 735-738.

Zimmerberg, B., and Kajunski, E. W. (2004). Sexually dimorphic effects of postnatal allopregnanolone on the development of anxiety behavior after early deprivation. Pharmacol. Biochem. Behav. 78, 465-471.

Zimmerberg, B., Rackow, S. H., and George-Friedman, K. P. (1999). Sexdependent behavioral effects of the 
neurosteroid allopregnanolone $(3 \alpha$, $5 \alpha$-THP) in neonatal and adult rats after postnatal stress. Pharmacol. Biochem. Behav. 64, 717-724.

Conflict of Interest Statement: The authors declare that the research was conducted in the absence of any commercial or financial relationships that could be construed as a potential conflict of interest.

Received: 24 August 2011; paper pending published: 24 September 2011; accepted: 14 November 2011; published online: 05 December 2011.
Citation: Gunn BG, Brown AR, Lambert JJ and Belelli D (2011) Neurosteroids and $G A B A_{A}$ receptor interactions: a focus on stress. Front. Neurosci. 5:131. doi: 10.3389/fnins.2011.00131

This article was submitted to Frontiers in Neuroendocrine Science, a specialty of Frontiers in Neuroscience.
Copyright (c) 2011 Gunn, Brown, Lambert and Belelli. This is an open-acces article distributed under the terms of the Creative Commons Attribution Non Commercial License, which permits noncommercial use, distribution, and reproduction in other forums, provided the original authors and source are credited. 